\title{
A New Image Fusion Technique Based on Directive Contrast
}

\author{
Gaurav Bhatnagar* and Balasubramanian $\operatorname{Raman}^{\dagger}$ \\ *广 Departmen of Mathematicst, Indian Institute of Technology Roorkee, Roorkee-247 667,India \\ *goravdma@gmail.com, ${ }^{\dagger}$ balaiitr@ieee.org
}

Received 27 August 2008; accepted 23 June 2009

\begin{abstract}
For making an image, which is more suitable for segmentation, feature extraction, object recognition, and Human Visual System, image fusion is frequently used technique. It combines complimentary information from different images of the same scene in a single image. In this paper, a simple but efficient algorithm is presented for image fusion employed in wavelet packet domain. For fusion, all the source images are decomposed into low and high frequency sub-bands and then fusion of high frequency sub-bands is done by the means of Directive Contrast while for low frequency median values is used. To reconstruct the fused image, inverse wavelet packet transform is performed. The performance of the algorithm is carried out by the experimental evaluation and the comparison is carried out with the existing algorithms
\end{abstract}

Key Words: Image Fusion; Multiresolution Analysis; Wavelet Packet Transform; Directive Contrast.

\section{Introduction}

The information science research associated with the development of sensory system focuses mainly on how information about the world can be extracted from the sensory data. In general, a single sensor is not sufficient to provide an accurate view of the real world. Hence, for the improvement in the capabilities of the intelligent machines and systems, the concept of multiple sensors was presented. Consequently, since past few years, multi-sensor fusion has become an important area of research and development. The single representation of different sources of sensory information is called multi-sensor fusion [1-4]. Multi-sensor fusion can occur at the signal, image or feature. At most all the advanced sensors of today, for example, optical cameras, millimetre wave (MMW) cameras, infrared cameras, x-ray imagers, radar imagers etc provide the information in the form of images. In the image-based application fields, image fusion has emerged as a promising research area. Hence, image fusion is the process of combining two or more images into a single image having important features of all and containing more accurate description of the scene than any of the individual source images.

The simplest way for image fusion is pixel-by-pixel [5] gray level average of the source images but this way leads to undesirable side effects such as reduced contrast. In the recent years, many image fusion methods have been proposed, such as statistical [6] and numerical methods, hue-saturation- intensity (HSI) method, principal component analysis (PCA) method [7-9], independent component analysis (ICA) method[10], image gradient [11,12] and contrast [13] pyramid and multiresolution methods [14-26].

Correspondence to: <goravdma@gmail.com>

Recommended for acceptance by <Xavier Otazu>

ELCVIA ISSN: 1577-5097

Published by Computer Vision Center / Universitat Autonoma de Barcelona, Barcelona, Spain 
Statistical and numerical methods involve huge computation using floating-point arithmetic; therefore these methods are time and memory consuming. The HSI method is based on the representation of low spatial resolution images using HSI system and then substitution of the intensity component by a high-resolution image. In PCA method, original images are transformed into uncorrelated images and then fused by choosing the maximum value among all. PCA is frequently used for fusion because of its ability to compact the redundant data into fewer bands.

In the recent years, fusion methods based on image gradient pyramid and multiresolution analysis have become very popular. Basic idea behind these methods is that the source images are decomposed by applying pyramid or wavelet transform, then fusion operation is performed on the transformed images. These methods produce very good results in less computation time and less memory. Burt et al. [11] have suggested a method in which the images are decomposed into gradient pyramid. Taking into account the variances in a $3 \times 3$ or $5 \times 5$ window, activity measure of each pixel is computed. Larger value is chosen based on this measure. Li et al. [16] have used similar method except the fact that for decomposition, discrete wavelet transformation (DWT) is used and consistency verification is also done along with the area based activity measure and maximum selection. Li et al. [17] have presented a region-based image fusion algorithm in multiresolution domain via segmentation. Authors obtain a shared multiresolution region representation to label all the input images from the multiresolution region representations. The fusion process is guided by these multiresolution region representations. The multiresolution segmentations of source images to be fused are obtained by fuzzy c-mean clustering. Huang et al. [18] have proposed a pixel level fusion algorithm using wavelet transform. For fusing high frequency part salience feature is used while low frequency part is fused according to their similarity. Pu et al. [20] have suggested a contrast based image fusion method employed in the wavelet domain. After decomposition, directive contrast is computed for all the decomposed images to fuse them.

In this paper, two fusion algorithms based on directive contrast in wavelet packet transform (WPT) domain are presented. In these schemes, we have improved the method proposed by Pu et al. [20]. First we extend the concept of directive contrast for WPT domain (given in section 3). The benefit of WPT over DWT is that WPT allows better frequency localization of signals wherever we want as many small values as possible whereas the standard wavelet transform may not produce the best result because it is limited to wavelet bases (the plural of basis). WPT increases by a power of two in each step. The comparison, which is made by us, shows that the performances of proposed algorithms are better than existing methods (PCA (MS), Burt et al. [11], Toet et al. [13], Pu et al. [20] ) .

The rest of the paper is organized as follows. The wavelet packet transform and directive constrast are explained in section 2 and 3. In section 4, proposed fusion algorithm is introduced. The experimental results are presented in section 5. Finally, the concluding remarks are given in section 6.

\section{Wavelet Packet Transform}

The wavelet packet transform (WPT) [27-30] generalizes the discrete wavelet transform and provides a more flexible tool for the time-scale analysis of the data. All advantages of the wavelet transform are retained because the wavelet basis is in the repertoire of bases available with the wavelet packet transform. Given this, the WPT may eventually become a standard tool in signal and image processing.
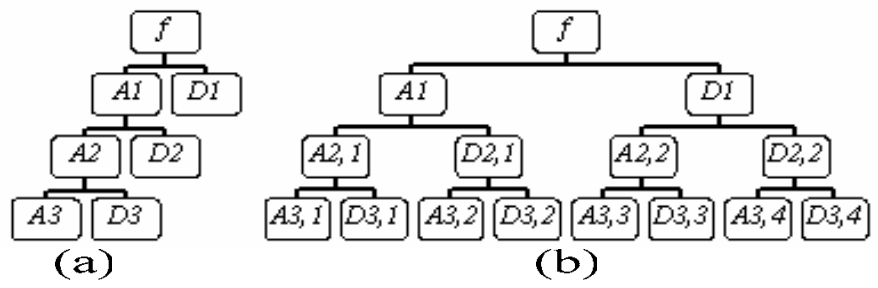

Figure 1: Difference between DWT and DWPT a) DWT b) DWPT

Using a pair of low and high-pass filters to split a space corresponds to splitting the frequency content of a signal into roughly a low and high-frequency component. In wavelet decomposition, we leave the highfrequency part alone and keep splitting the low-frequency part whereas in wavelet packet decomposition, the 
high-frequency part is also split into a low and a high-frequency part. Hence in general, wavelet packet decomposition divides the frequency space into various parts and allows better frequency localization of the signals. In figure 1, the tree structure is given for DWT and WPT, DWT produces a binary tree structure (figure 1(a)) while WPT produces the complete binary tree structure (figure 1(b)).

\section{Directive Contrast}

According to Human Visual System (HVS) the local luminance contrast of images is defined as[13,20,21]:

$$
C=\frac{L-L_{B}}{L_{B}}=\frac{L_{H}}{L_{B}}
$$

where $L$ and $L_{B}$ represent the local luminance and the luminance of the local background. Generally, $L_{B}$ is regarded as local low frequency and hence, $L-L_{B}=L_{H}$ is treated as local high frequency. On the above discussion, a modified sequence of directive contrast is presented for WPT domain. In WPT domain, sequence of directive contrast is defined in two different ways based on the approximation part (low frequency) selection.

\subsection{First Definition of Directive Contrast for Wavelet Packet Transform Domain}

In this definition, we consider main approximation part as the lowest frequency as shown in the figure 2(a). Since, we select main approximation part as low frequency for finding directive contrast. As a result, some approximation parts are remaining. Therefore, we get four-directive contrast namely Approximate, Horizontal, Vertical and Diagonal Contrast. Hence, a modified sequence of directive contrast for $l$ level WPT is defined as:

$\left.\begin{array}{ll}\text { Approximate Contrast: } C_{l, i}^{A}=\frac{A_{l, i}}{A_{l, 1}}, i \neq 1 \\ \text { Horizontal Contrast: } \quad C_{l, i}^{H}=\frac{H_{l, i}}{A_{l, 1}} \\ \text { Vertical Contrast: } \quad C_{l, i}^{V}=\frac{V_{l, i}}{A_{l, 1}} \\ \text { Diagonal Contrast: } \quad C_{l, i}^{D}=\frac{D_{l, i}}{A_{l, 1}}\end{array}\right\} 1 \leq i \leq 2^{l+1}$

\begin{tabular}{|c|c|c|c|c|c|c|c|}
\hline $\mathrm{A}_{3,1}$ & $\mathrm{H}_{3,1}$ & $\mathrm{~A}_{3,2}$ & $\mathrm{H}_{3,2}$ & $A_{3,2}$ & $\mathrm{H}_{3,2}$ & $\mathrm{~A}_{3,4}$ & $\mathrm{H}_{3}$ \\
\hline$V_{3,1}$ & $\mathrm{D}_{3,1}$ & $V_{3,2}$ & $\mathrm{D}_{3,2}$ & $V_{3,3}$ & $\mathrm{D}_{3,3}$ & $V_{3,4}$ & \\
\hline$A_{3,5}$ & $\mathrm{H}_{3,5}$ & $\mathrm{~A}_{3,6}$ & $\mathrm{H}_{3,6}$ & $\mathrm{~A}_{3,7}$ & $\mathrm{H}_{3,7}$ & $\mathrm{~A}_{3, \varepsilon}$ & \\
\hline$V_{3, \xi}$ & $\mathrm{D}_{3,5}$ & $V_{3,6}$ & $\mathrm{D}_{3,6}$ & $V_{37}$ & $\mathrm{D}_{3,7}$ & $\mathrm{~V}_{3, \S}$ & \\
\hline$A_{3,9}$ & $\mathrm{H}_{3,9}$ & $A_{3,10}$ & $\mathrm{H}_{3,1 \mathrm{c}}$ & $A_{3,11}$ & $\mathrm{H}_{3,11}$ & $A_{3,12}$ & \\
\hline$V_{3,9}$ & $\mathrm{D}_{3,9}$ & $V_{3,1 c}$ & $\mathrm{D}_{3,1 \mathrm{c}}$ & $V_{3,11}$ & $\mathrm{D}_{3,11}$ & $V_{3,12}$ & \\
\hline$A_{3,13}$ & $\mathrm{H}_{3,13}$ & $\mathrm{~A}_{3,14}$ & $\mathrm{H}_{3,14}$ & $A_{3,15}$ & $\mathrm{H}_{3,15}$ & $\mathrm{~A}_{3,1 \epsilon}$ & \\
\hline & & & & & & & \\
\hline
\end{tabular}

(a)

\begin{tabular}{|c|c|c|c|c|c|c|c|}
\hline $\mathrm{A}_{3,1}$ & $\mathrm{H}_{3,1}$ & $\mathrm{~A}_{3,2}$ & $\mathrm{H}_{3,2}$ & $A_{3,2}$ & $\mathrm{H}_{3,2}$ & $\mathrm{~A}_{3,4}$ & \\
\hline$\overline{V_{3,1}}$ & $\mathrm{D}_{3,1}$ & $\mathrm{~V}_{3,2}$ & $\mathrm{D}_{3,2}$ & $\mathrm{~V}_{3,2}$ & $\mathrm{D}_{3,2}$ & $V_{3,4}$ & \\
\hline$A_{3,5}$ & $\mathrm{H}_{3,5}$ & $\mathrm{~A}_{3,6}$ & $\mathrm{H}_{3,6}$ & $A_{3,7}$ & $\mathrm{H}_{3,7}$ & $A_{3,8}$ & \\
\hline$V_{3,5}$ & $\mathrm{D}_{3,5}$ & $V_{3,6}$ & $\mathrm{D}_{3,6}$ & $V_{3,7}$ & $\mathrm{D}_{3,7}$ & $V_{3,8}$ & \\
\hline$A_{3,9}$ & $\mathrm{H}_{3,9}$ & $\mathrm{~A}_{3,1 \mathrm{C}}$ & $\mathrm{H}_{3,1}$ & $A_{3,11}$ & $\mathrm{H}_{3,1}$ & & \\
\hline$\overline{V_{3,9}}$ & $\mathrm{D}_{3,9}$ & $V_{3,1 C}$ & $\mathrm{D}_{3,1 \mathrm{C}}$ & $V_{3,11}$ & $\mathrm{D}_{3,11}$ & $V_{3,12}$ & \\
\hline$A_{3,13}$ & $\mathrm{H}_{3,1}$ & & & $\mathrm{~A}_{3,15}$ & $\mathrm{H}_{3,1}$ & & \\
\hline & & & & & & & \\
\hline
\end{tabular}

(b)

Figure 2: Bolded block is the low frequency part for finding directive contrast using 3-level DWPT of an image a) First definition b) Second definition of Directive Contrast 


\subsection{Second Definition of Directive Contrast for Wavelet Packet Transform Domain}

In this definition, we select different low frequency for each level as shown in the figure 2(b). Since, different low frequency sub-bands are selected level wise for finding directive contrast therefore, we get three-directive contrast namely Horizontal, Vertical and Diagonal Contrast. Hence, a modified sequence of directive contrast for $l$ level WPT is defined as:

$$
\left.\begin{array}{ll}
\text { Horizontal Contrast: } & C_{l, i}^{H}=\frac{H_{l, i}}{A_{l, i}} \\
\text { Vertical Contrast: } & C_{l, i}^{V}=\frac{V_{l, i}}{A_{l, i}} \\
\text { Diagonal Contrast: } & C_{l, i}^{D}=\frac{D_{l, i}}{A_{l, i}}
\end{array}\right\} 1 \leq i \leq 2^{l+1}
$$

\section{Proposed Fusion Algorithm}

In this section, we discuss some motivating factors in design of our approach to image fusion. We use DWPT and directive contrast for developing the algorithm. This scheme inherits advantages of both DWT and DWPT, i.e, better localization of low as well as high frequency. For our convenience, only two source images are considered in our experiments. Let they be $F_{1}$ and $F_{2}$. For fusion, the basic condition is that the sizes of all source images are same. Hence without loss of generality, let us consider, source images are of size $M \times N$. The block diagram of the proposed fusion algorithm is given in figure 3 . The fusion algorithm is given as follows:

- First, all the source images are l-level decomposed by the means of discrete wavelet packet transform (DWPT).

- Find the sequence of directive contrast for each frequency. Let us denote $C_{l}^{\theta, 1}, C_{l}^{\theta, 2}$ are the directive contrast for first and second image respectively, where $\theta \in[A, H, V, D]$ and $l$ is the decomposition level.

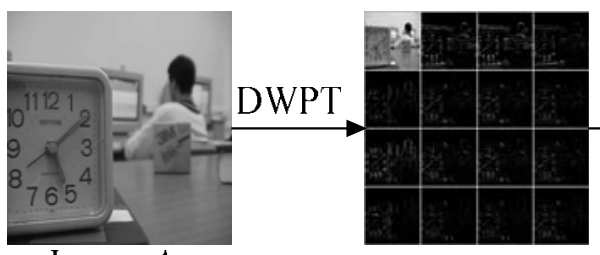

Image A

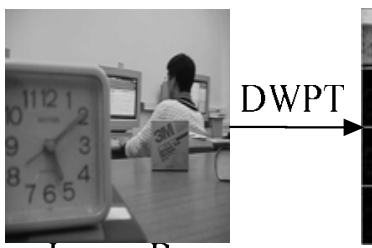

lmage B

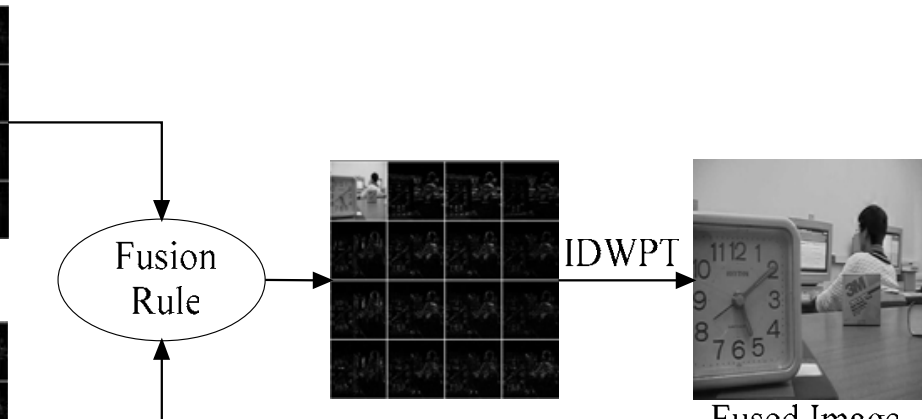

Fused Image

Figure 3: Block diagram of Proposed Algorithm 
- High frequency components are fused using directive contrast of corresponding pixels in all source images.

$$
\begin{aligned}
H_{l, i}^{\text {new }} & = \begin{cases}H_{l, i}^{1} & \text { if }\left|C_{l, i}^{H, 1}\right| \geq\left|C_{l, i}^{H, 2}\right| \\
H_{l, i}^{2} & \text { otherwise }\end{cases} \\
V_{l, i}^{\text {new }} & = \begin{cases}V_{l, i}^{1} & \text { if }\left|C_{l, i}^{V, 1}\right| \geq \mid C_{l, i}^{V, 2} \\
V_{l, i}^{2} & \text { otherwise }\end{cases} \\
D_{l, i}^{\text {new }} & = \begin{cases}D_{l, i}^{1} & \text { if }\left|C_{l, i}^{D, 1}\right| \geq\left|C_{l, i}^{D, 2}\right| \\
D_{l, i}^{2} & \text { otherwise }\end{cases}
\end{aligned}
$$

If first definition of directive contrast is used then

$$
A_{l, i}^{\text {new }}= \begin{cases}A_{l, i}^{1} & \text { if }\left|C_{l, i}^{A, 1}\right| \geq\left|C_{l, i}^{A, 2}\right| \\ A_{l, i}^{2} & \text { otherwise }\end{cases}
$$

- For the fusion of low frequency (approximate part) we use median instead of averaging.

$$
A_{l}^{\text {new }}=\operatorname{median}\left(A_{l}^{1}, A_{l}^{2}\right)
$$

- Perform $l$-level inverse discrete wavelet packet transform to construct fused image.

For the merging of low frequency components, median is used instead of averaging. The main reason for choosig median is come from statistical theory. According to the statistical theory, averaging has some drawbacks neither it can be determined by inspection nor it can be located graphically, it cannot be determined when one or more data is missing and mainly it is affected very much by extreme values. Where as median is the middle of a distribution: half the values are above the median and half are below the median. The meadian can be viewed as a value such that the number of data above is equal to the number of data below. Hence, median is a positional average. Moreover, median is determined when one or more data is missing and it is not at all affected by extreme values and this makes it a better measure than the mean. In the case of two data, median concides with average value of given data.

\section{$5 \quad$ Results and Discussions}

Some general requirements for fusion algorithms are: (1) it should be able to extract complimentary features from input images, (2) it must not introduce artifacts or inconsistencies according to Human Visual System and (3) it should be robust and reliable. Generally, these requirements are often very difficult to achieve. One of the most critical problems is that there is a lack of reliable and efficient methods to validate fusion algorithms. The best method to validate the fusion algorithm is that some human observers are asked to view a series of fused images and rate them. These tests are typically accurate if performed correctly but they are inconvenient, expensive and time consuming. Hence, there is a need of creating an evaluation system. Hence, first an evaluation index system is established for evaluating proposed fusion algorithm. These indices are determined according to statistical parameters. This evaluation index system includes mean, standard deviation, entropy, average gradient, peak signal to noise ratio (PSNR) and correlation coefficients. Among these mean, standard deviation, entropy, average gradient reflect spatial details information whereas PSNR and correlation coefficient reflects spectral information.

\subsection{Evaluation indices for evaluating fusion algorithm}

Image evaluation indices are used to evaluate the quality of the fused image. Definition of these indices and their physical meanings are given as follows. 
1) Mean and Standard Deviation: In statistical theory, mean and standard deviation are defined as follows:

$$
\begin{gathered}
\hat{\mu}=\frac{1}{N} \sum_{i=1}^{N} x_{i} \\
\hat{\sigma}^{2}=\frac{1}{N-1} \sum_{i=1}^{N}\left(x_{i}-\hat{\mu}\right)^{2}
\end{gathered}
$$

Where $N$ is the total number of pixels in the image and $x_{i}$ is the value of the $i^{\text {th }}$ pixel.

2) Entropy: Entropy is the measure of information quantity contained in an image. If the value of entropy becomes higher after fusion then the information quality will increase. Mathematically, entropy is defined as:

$$
E=-\sum_{i=1}^{N} p\left(x_{i}\right) \ln p\left(x_{i}\right)
$$

where $p\left(x_{i}\right)$ is the probability of the occurrence of $x_{i}$.

3) Difference Entropy: Difference Entropy is the measure of the difference between the average amount of information between ideal and fused image. Mathematically, difference entropy is defined as:

$$
\Delta E=\left|E_{\text {ideal }}-E_{\text {fused }}\right|
$$

where $E_{\text {ideal }}$ and $E_{\text {fused }}$ are the entropy of the ideal and fused image.

4) Average Gradient: The average gradient is given by:

$$
\bar{g}=\frac{1}{N} \sum \sqrt{\frac{\Delta I_{x}^{2}+\Delta I_{y}^{2}}{2}}
$$

where $\Delta I_{x}, \Delta I_{y}$ are the differences in $x$ and $y$ direction. The larger the average gradient, the sharper the image.

5) Peak Signal to Noise Ratio: The PSNR indicates the similarity between two images. The higher the value of PSNR, the better the fused image is.

$$
P S N R=10 \lg \frac{255^{2}}{R M S E^{2}}
$$

where RMSE (root mean square error) is defined as

$$
\operatorname{RMSE}^{2}=\frac{1}{M N} \sum \sum\left[F_{1}(i, j)-F_{2}(i, j)\right]^{2}
$$

6) Correlation Coefficient: The correlation coefficient is a number lying between $[0,1]$ that measures the degree in which two variables are linearly related. Correlation coefficient is given by:

$$
\rho=\sqrt{\frac{\sum_{i=1}^{M} \sum_{j=1}^{N}\left[F_{\text {ideal }}(i, j)-F_{\text {fused }}(i, j)\right]^{2}}{M N}}
$$

where $F_{\text {ideal }}$ is the ideal image and $F_{\text {fused }}$ is the fused image. Lower values of $\rho$ indicate greater similarity between the $F_{\text {ideal }}$ and $F_{\text {fused }}$ images.

\subsection{Experimental Results}

We have demonstrated the performance of the proposed fusion algorithm using MATLAB, by taking different experimental images. The experimental images are divided into five categories namely 
Defocused/Multi-focus images, Medical images, Military Surveillance, Concealed Weapon Detection and Colour images. For all these images, results of proposed algorithms are compared with the traditional PCA (MS rule), Gradient and Contrast Pyramid [11, 13] and Pu [20] methods.

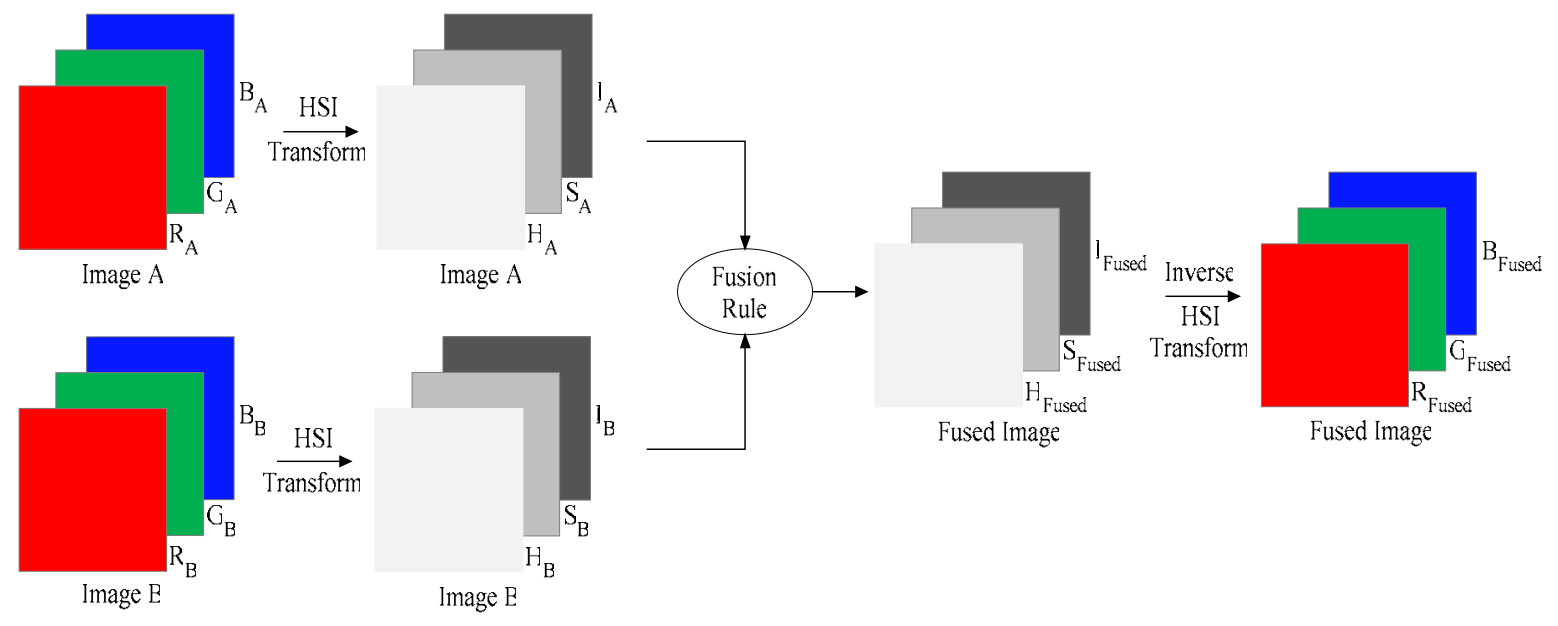

Figure 4: Block Diagram for fusion of colour images

For the fusion of colour images, first the colour (RGB) image is transformed into Hue-SaturationIntensity (HSI) image and then apply proposed algorithm on all the three parts of the source images. Once, fused hue, intensity and saturation parts are obtained, inverse HSI transform is performed to construct the fused RGB image. The procedure for RGB image fusion is given in figure 4 . The basic idea behind the use of HIS transform is to eliminate the spatial correlation among the input components ( $R, G$ and $B$ components) by decomposing them into three independent components that easily correlate to human perception. The basic model treats intensity as the vertical axis, hue as the circumferential angle, and saturation as radius of a cylindrical coordinate system. It is an alternate, application oriented, colour space to represent given data more objectively. Intensity relates to the overall brightness of a colour or energy level of the light and is devoid of any colour content. It shows how close it is to black or white. Hue refers to the dominant or average wavelength of light contributing to a colour, i.e. the actual perceived colour such as red, blue, green, etc. Saturation specifies the degree to which the colour is pure from white light (grayscale) dilution or pollution. The transformation from RGB colour space to IHS space is nonlinear, lossless and reversible. One can vary each of the IHS components without affecting the others. The proposed image fusion technique is also used for multispectral images. A multispectral image consists of several bands of data. For visual display, each band of the image may be displayed one band at a time as a gray scale image, or in combination of three bands at a time as a colour composite image. The proposed fusion technique is applicable for both gray-scale and colour images and hence, applicable to multispectral images. For multispectral images apart from used evaluation indices, there are some more evaluation indices namely ERGAS, RASE, SAM, SID, Qavg. If proposed fusion algorithm is used for multispectral images then these indices also taken into consideration.

\subsubsection{Results for Defocused/Multi-focus Images}

Mandrill, pepper, hoed and pepsi images are used as test images for this section. Mandrill, peppers and pepsi images are of size $512 \times 512$ whereas hoed image is of size $256 \times 256$. In mandrill images, we concentrate on upper and lower half parts (figure 5). In pepper images, we concentrate on left and right half parts (figure 6). In hoed images, we concentrate on middle and outer parts (figure 7). In pepsi images, pepsi container and barcode are concentrated (figure 8). Among these images, mandrill and peppers images are simulated image pair which are generated by filtering the given images with $13 \times 13$ Gaussian window and given images are treated as ideal images. Pepsi images are multifocus images, obtained with two different focal planes. 


\subsubsection{Results for Medical Images}

In medical diagnostics, new imaging methods, such as, computed tomography (CT), ultrasound, positron emission tomography (PET), nuclear magnetic resonance (NMR) etc., assist the physician to localize the abnormal masses and give an easy overview of the anatomic detail. All these imaging methods have their own characteristics and drawbacks. As an example, the excellent views of bones and other dense structures are given by CT images whereas the excellent views of soft tissues are given perfectly by MR images. In certain situations, both soft and dense tissues are used to be visualized simultaneously for better diagnosis. Hence, there is a need of the fusion of images of various kinds for better treatment planning. The following images illustrate the fusion of a CT and a MRI image of brain (figures 9 and 10). Both the pair of experimental images are real images taken from two different sensors i.e. computed tomography and magnetic resonance image.

\subsubsection{Results for Military Surveillance}

A wide application of Image Fusion is in Military surveillance. Two examples are illustrated below of a scene captured from different sensors. In first example (figure 11), first image is a visual image which illustrates a ship, smoke and a mountain in the background. Second image is an infrared (IR) sensor image of the same scene, which shows a ship and a helicopter. After fusion of these two images, the correctness of target recognition and tracking are improved. Second example (figure 12) is the tracking of the tank in the battlefield. First image is the image of a moving tank in which tank is motion blurred but the background is clearly visible. While in the second image, tank is clearly visible but the background is not clear. Hence, fused image preserves all the useful information from the source images.

\subsubsection{Results for Concealed Weapon Detection (CWD)}

Due to new and emerging threats to the smuggling of weapons through the security checkpoints, by both the domestic and foreign terrorists, Concealed weapon detection (CWD)[22] has become a burning problem now a days. Image fusion has been identified as a key technology to enable concealed weapon detection. First, the visual image of suspect is taken and then IR or millimeter waves (MMW) images are taken. Basic terminology for concealed weapon detection is the fusion of the visual and IR or millimeter waves (MMW) images of suspect. Figure 13 shows a pair of visual and MMW images. The visual image gives the information of the appearance of the people while the MMW image shows the existence of a gun. Fused image provides the information of the person with concealed gun underneath his clothes. Figure 14 demonstrates another example of CWD.

\subsubsection{Results for Colour Images}

Balloon, book, house and rose images are used as experimental images for this sub sub-section. Book, house and rose images are of size $512 \times 512$ whereas balloon image is of size $256 \times 256$. All these images are the examples of multi-focus images. Figures 15, 16, 17 and 18 show the results for Balloon, Book, House and Rose images respectively. All these images are multifocus images, obtained with two different focal planes.

The comparison of statistical parameters for merged images according to different fusion algorithms are shown in tables 1, 2, 3, 4 and 5 for the defocused/multi-focus, medical, Military Surveillance, concealed weapon detection and colour images respectively where as the visual assessment can be found in figures 518 for all images. It is clear that proposed algorithms better preserve spectral information but also improve the spatial detail information than the existing algorithms. If proposed algorithms are compared then the fusion using second definition of Directive Contrast performs better. The PCA algorithm gives baseline results. Except one or two cases, these methods have poor results relatively to others algorithms. This was expected because this method has no scale selectivity. This limitation is rectified in multiresolution algorithms. For some of the experimental images, difference entropy, PSNR and correlation coefficient are not shown, since proper ideal image is not available to compare our results. 
In table 1, results for defocus/multifocus images are given. The performance of Toet et al. [13] is best among all existing and proposed methods. PCA method gives the baseline results. Burt et al. [11] and Pu et al. [20] give better results than PCA method. The proposed methods perform better compared to $\mathrm{Pu}$ et al. [20]. Among all the proposed methods, the performance of method using second definition of directive contrast is better. Hence, best results for defocus/multifocus images are obtained by Toet et al. [13] and proposed method using second definition of directive contrast. To reach this conclusion the main stress is focused on the entropy, difference entropy, average gradient, PSNR and correlation coefficient evaluation indices which have the highest/lowest values between the compared methods.

In table 2, results for medical images are given. In this case, PCA method is performing best among all existing and proposed methods while the baseline results are obtained by Toet et al. [13] method. Burt et al. [11] and $\mathrm{Pu}$ et al. [20] are giving better results than Toet et al. [13] method. The proposed method using second definition of directive contrast performs better as compared to Burt et al. [11] and $\mathrm{Pu}$ et al. [20] methods. Hence, best results for medical images are obtained by PCA and proposed method using second definition of directive contrast. To reach this conclusion the main stress is focused on the mean, standard deviation, entropy and average gradient evaluation indices which have the highest/lowest values between the compared methods.

In tables 3, 4 and 5, results for Military surveillance, concealed weapon detection and colour images are given respectively. In this case, PCA and Toet et al. [13] methods are giving baseline results while Burt et al. [11] and Pu et al. [20] performs relatively better than PCA and Toet et al. [13] methods. The proposed methods perform better compared to existing methods. The performance of the proposed method using second definition of directive contrast is best among existing methods. Hence, best results are obtained by proposed method using second definition of directive contrast. To reach this conclusion the main stress is focused on the mean, standard deviation, entropy and average gradient evaluation indices which have the highest/lowest values between the compared methods.

\section{Conclusions}

The fusion methods described in this paper cover a large variety of practical applications. The presented fusion technique has been intended to help in understanding the current state of knowledge in this research area. In our proposed techniques, we are using Wavelet Packet Transform instead of Discrete Wavelet Transform. The main benefit of WPT is that it allows better frequency localization of the signals. Using this, we produce as many small values as possible, according to our problem. The extended definitions of directive contrast are mathematically more accurate than the common definition. It provides visually and numerically better-fused images than the existing algorithms. We claimed that the contrast-based wavelet packet fusion can do a better job than the existing fusion methods, taking into account of mean, standard deviation, entropy, average gradient, PSNR and correlation coefficient.

\section{Acknowledgement}

One of the authors, Gaurav Bhatnagar, gratefully acknowledges the financial support of the Council of Scientific and Industrial Research, New Delhi, India, through his Junior Research Fellowship (JRF) scheme (CSIR Award no.: 09/143(0559)/2006-EMR-I) for his research work. The author, R. Balasubramanian, gratefully acknowledges the financial support of Sponsored Research and Industrial Consultancy (SRIC), Indian Institute of Technology Roorkee, India under the grant number MHR03-05-802. He also acknowledges the financial support of Department of Science and Technology(DST), India under his fast track project for young scientist (DST-302-MTD) to carry out this research work.

\section{References}

[1] D.L. Hall, J. Llinas “An Introduction to Multisensor Data Fusion”, Proceedings of the IEEE, 85(1): 623, 1997. 
[2] C. Pohl and J.L.V. Genderen, "Multisensor Image Fusion in Remote Sensing: Concept, Method and Applications", International Journal of Remote Sensing, 19(5): 823-854, 1998.

[3] S. Li, Y. Wang, "Multisensor Image Fusion: Concept, Method and Applications", Advances in Modeling and Analysis, 45(3/4): 4.29-56, 2002.

[4] M.I. Smith, J.P. Heather, "A Review of Image Fusion Technology", Proceeding of SPIE, 29-45, 2005.

[5] C. Xydeas and V. Petrovic "Objective Pixel-level Image Fusion Performance Measure", Sensor Fusion: Architectures, Algorithms, and Applications IV, SPIE, 4051: 89-98, 2002.

[6] A. Cardinali, G.P. Nason, "A Statistical Multiscale Approach to Image Segmentation and Fusion", Proceedings of the 8th International Conference on Information Fusion, 475-482, 2005.

[7] R. Welch, W. Ahlers, "Merging multiresolution SPOT HRV and Landsat TM data", Photogrammetric Engineering \& Remote Sensing, 53(3): 301-303, 1987.

[8] P.S. Chavez, A.Y. Kwarteng, "Extracting spectral contrast in Landsat thematic mapper image data using selective principal component analysis", Photogrammetric Engineering and Remote Sensing, 55: 339-348, 1989.

[9] P.S. Chavez, S.C. Sides, J.A. Anderson, "Comparison of three different methods to merge multiresolution and multispectral data: Landsat TM and SPOT panchromatic", Photogrammetric Engineering and Remote Sensing, 57(3): 295-303, 1991.

[10] Nikolaos Mitianoudis, Tania Stathaki, "Adaptive image fusion using ICA bases", Proceedings of the IEEE Conf. Acoustics, Speech, and Signal Processing, 2: 829-832, 2006.

[11] P.J. Burt, R.J. Kolczynski, "Enhanced image capture through fusion", Proceedings of the 4th International Conference on Computer Vision, 173-182, 1993.

[12] V.S. Petrovic, C.S. Xydeas, "Gradient-based multiresolution image fusion", IEEE Trans. Image Processing, 13(2):228-37, 2004.

[13] A. Toet, L.J. Ruyven, J.M. Valeton, "Merging thermal and visual images by a contrast pyramid", Optical Engineering, 28: 789-792, 1989.

[14] G. Piella, "A general framework for multiresolution image fusion: from pixels to regions", Information Fusion, 4(4): 259-280, 2003.

[15] G. Qu, D. Zhang and P. Yan, "Medical Image Fusion by Wavelet Transform Modulus Maxima", Optics Express, 9: 184-190, 2001.

[16] H. Li, B.S. Manjunath, S.K. Mitra, "Multisensor image fusion using the wavelet transform", Graph Models Image Processing, 57(3): 235-245, 1995.

[17] Z.H. Li, Z.L. Jing, G. Liu, S.Y. Sun, H. Leung, "A Region-based Image Fusion Algorithm Using Multiresolution Segmentation", Proceedings of IEEE International Conference on Intelligent Transportation Systems, 96-101, 2003.

[18] X.S. Huang, Z. Chen, "A Wavelet-based Scene Image Fusion Algorithm", Proceedings of the IEEE TENCON'02, 602-605, 2002.

[19] G. Qu, D. Zhang, P. Yan, "Information measure for performance of image fusion", Electronics Letters, 38(7): 313-315, 2002.

[20] T. Pu, G. Ni, "Contrast based Image Fusion using the Discrete Wavelet Transform", Optical Engineering, 39(8): 2075-2082, 2000.

[21] D.A. Yocky, "Image merging and data fusion by means of the two-dimensional wavelet transform", J. Opt. Soc. Am. A, 12(9):1834-1841, 1995.

[22] J. Nunez, X. Otazu, O. Fors, A. Prades, V. Pala and R. Arbiol, "Image fusion with additive meltiresolution wavelet decomposition: applications to spot+landsat images", J. Opt. Soc. Am. A, 16: 467-474, 1999.

[23] J. Nunez, X. Otazu, O. Fors, A. Prades, V. Pala and R. Arbiol, "Multiresolution based image fusion with additive wavelet decompositions", IEEE Transactions on Geosciences and Remote Sensing, 37(3): 1204-1211, 1999. 
[24] E. Yu and R. Wang, "Fusion and Enhancement of the multispectral image with wavelet transform", Computer Engineering \& Science, 23(1): 47-50, 2001.

[25] R. Balasubramanian, G. Bhatnagar, “A new Contrast based Image Fusion using Wavelet Packets", Proceedings of the IEEE conference on Applications of Intelligent Systems, 141-145, 2008.

[26] Z. Liu, Z. Xue, R.S. Blum, R. Laganiere, "Concealed weapon detection and visualization in a synthesized image", Pattern Analysis \& Applications, 8(4): 375-389, 2006. (DOI: 10.1007/s10044005-0020-8)

[27] Z. Xiong, K. Ramchandran, M.T. Orchad, "Wavelet packet image coding using space-frequency quantization", IEEE Transactions on Image Processing, 7: 160-174, 1998.

[28] M. Feil and A. Uhl, "Multicomputer algorithms for Wavelet Packet image Compression", Proceedings of the 14th International Symposium on Parallel and Distributed Processing, 793-798, 2000.

[29] I. Daubechies, "The wavelet transform time-frequency localization and signal analysis", IEEE Transactions on Information Theory, 36: 961-1005, 1990.

[30] T. Posch, “The wavelet packet transform (WPT) as applied to signal processing”, Proceedings of IEEESP Intl. Sym. Time Frequency Time Scale Anal, 143-146, 1992. 


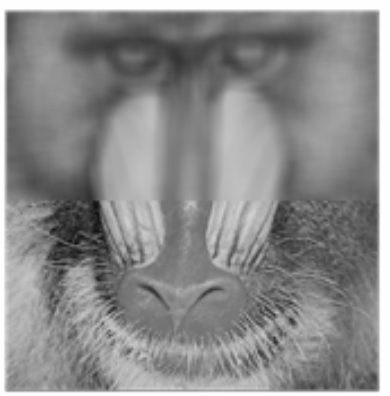

(a)

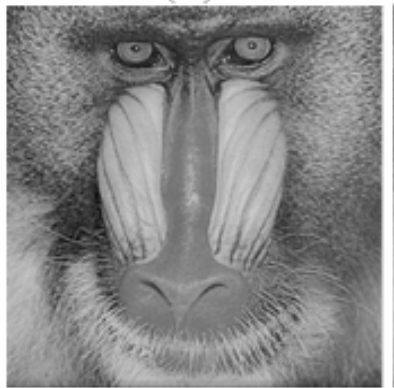

(e)

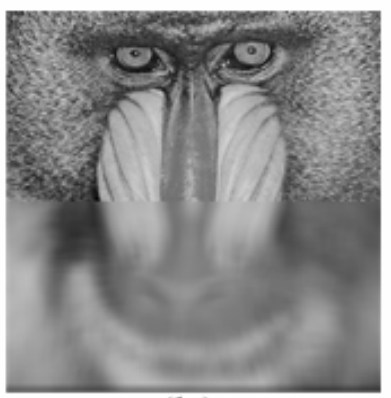

(b)

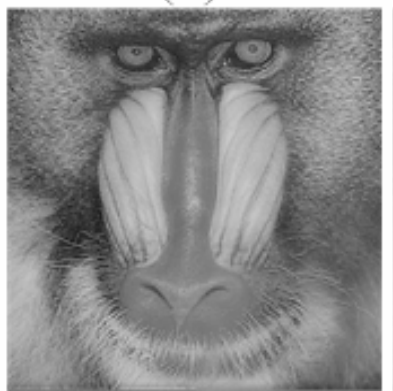

(f)

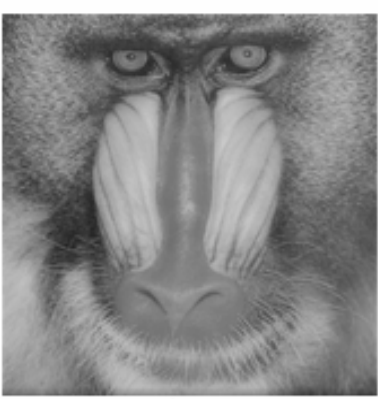

(c)

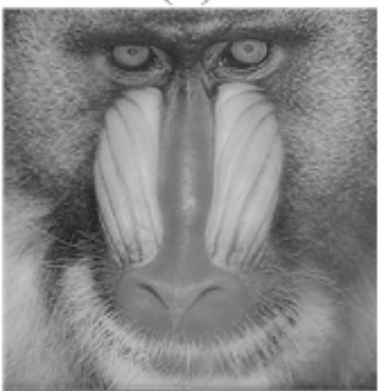

(g)

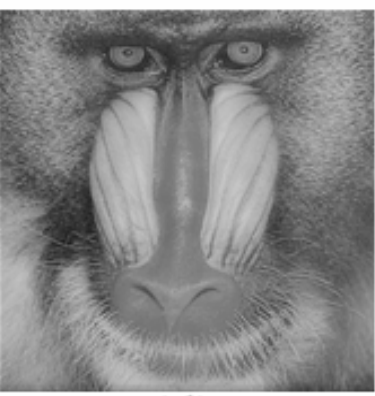

(d)

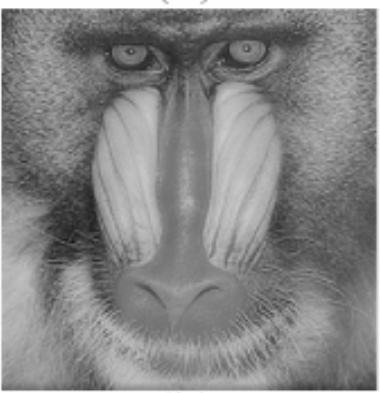

(h)

Figure 5: Results for mandrill image a) Upper side blurred image b) Lower side blurred image c) Result for PCA method d) Result for Contrast pyramid e) Result for Gradient Pyramid f) Result for Pu et al. [20] method g,h) Result for proposed method using first and second definition of directive contrast.

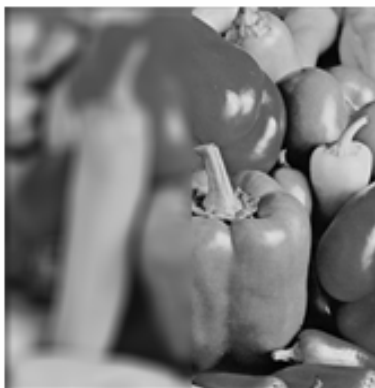

(a)

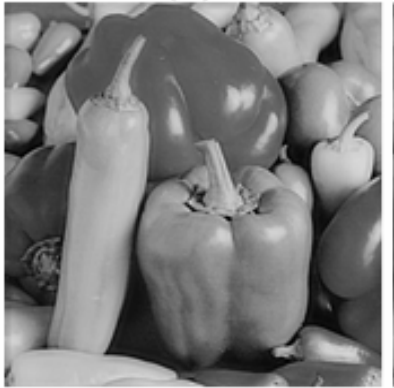

(e)

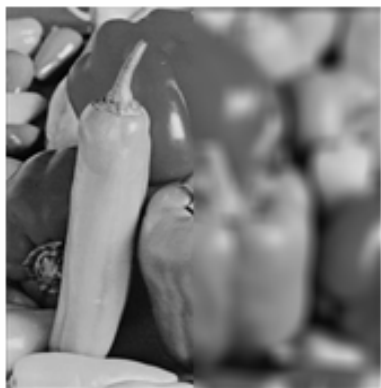

(b)

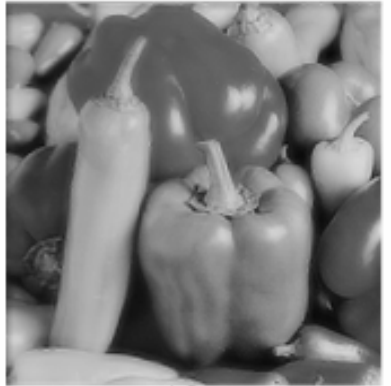

(f)

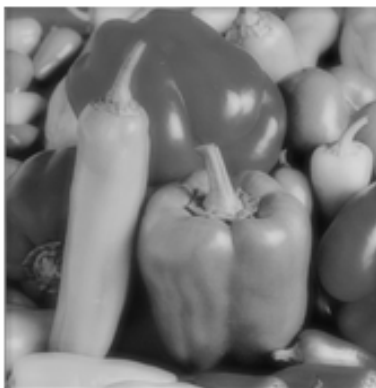

(c)

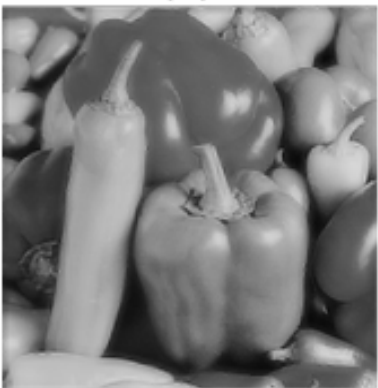

(g)

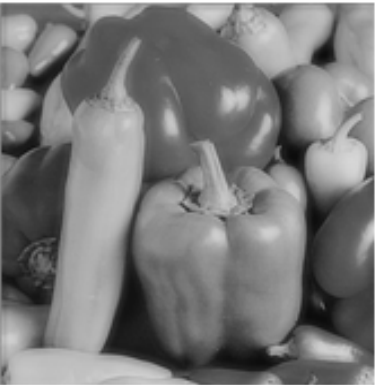

(d)

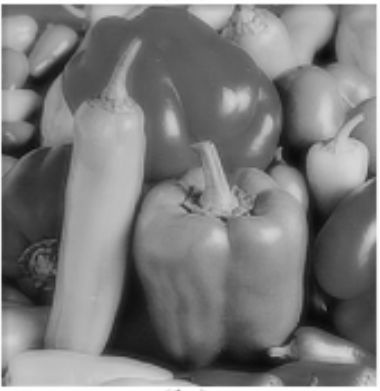

(h)

Figure 6: Results for pepper image a) Left side blurred image b) Right side blurred image c) Result for PCA method d) Result for Contrast pyramid e) Result for Gradient Pyramid f) Result for Pu et al. [20] method $\mathrm{g}, \mathrm{h}$ ) Result for proposed method using first and second definition of directive contrast. 


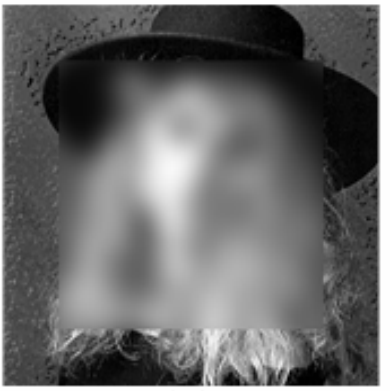

(a)

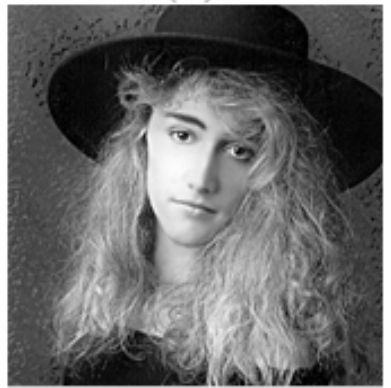

(e)

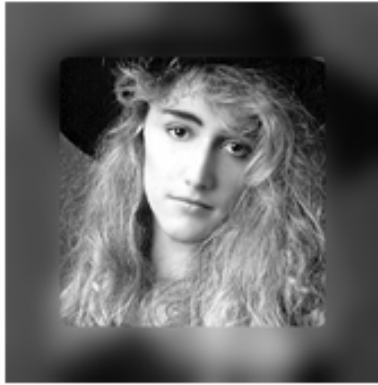

(b)

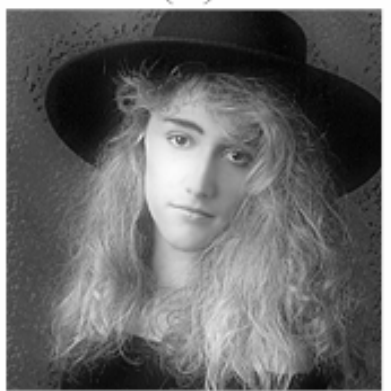

(f)

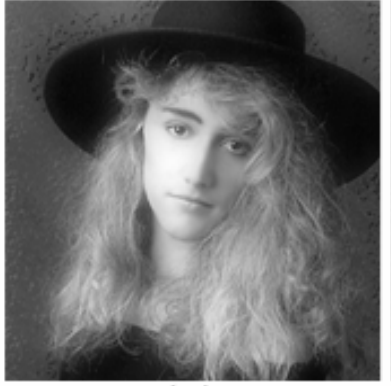

(c)

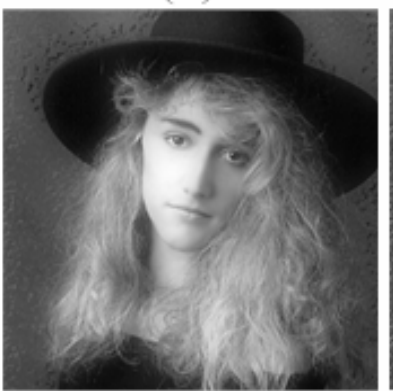

( $g$ )

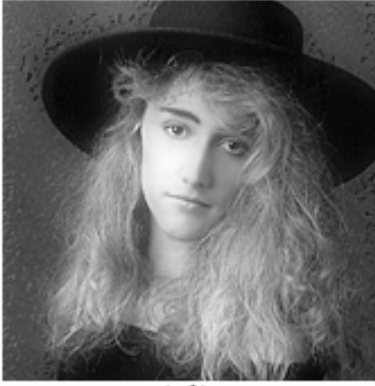

(d)

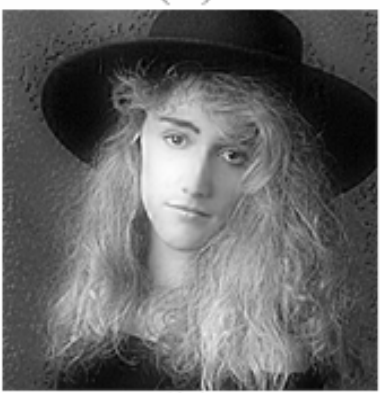

(h)

Figure 7: Results for hoed image a) Middle side blurred image b) Corner side blurred image c) Result for PCA method d) Result for Contrast pyramid e) Result for Gradient Pyramid f) Result for Pu et al. [20] method g,h) Result for proposed method using first and second definition of directive contrast.

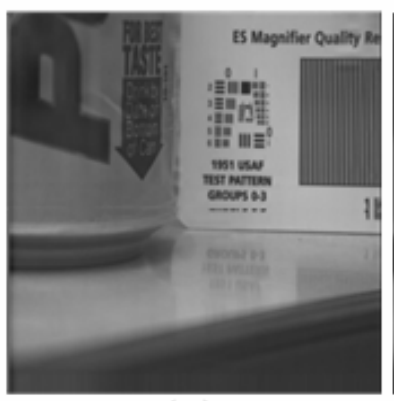

(a)

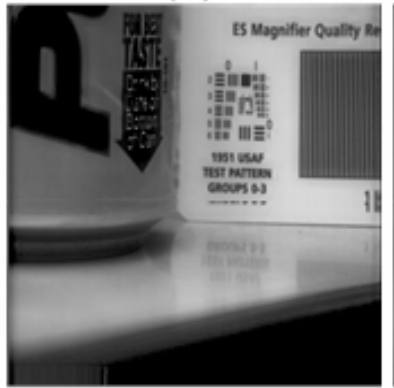

(e)

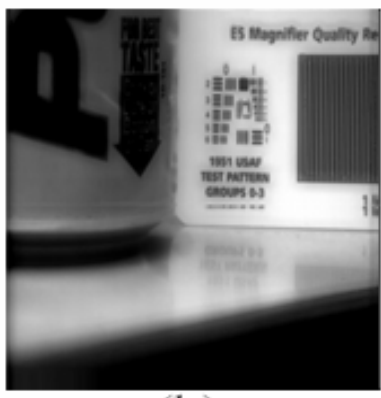

(b)

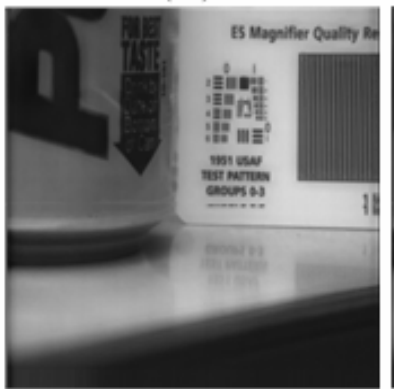

(f)

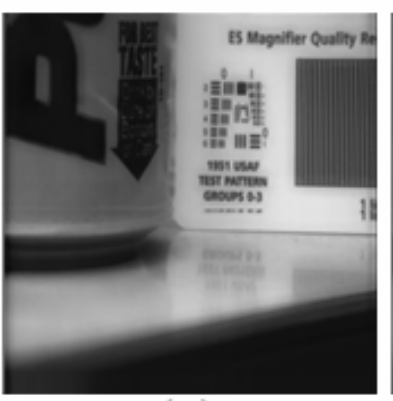

(c)

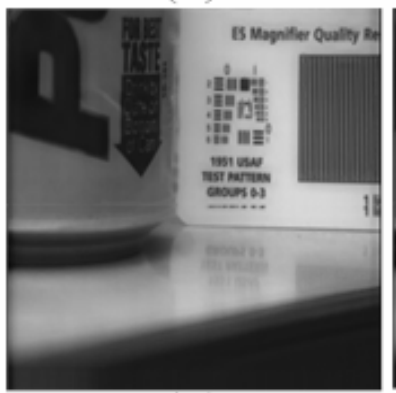

(g)

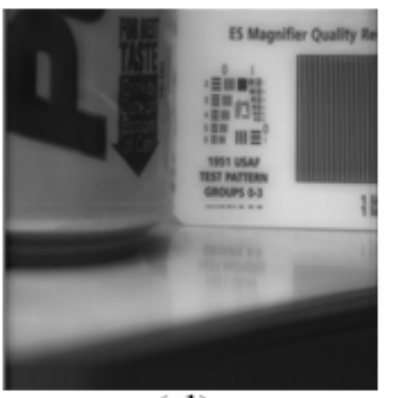

(d)

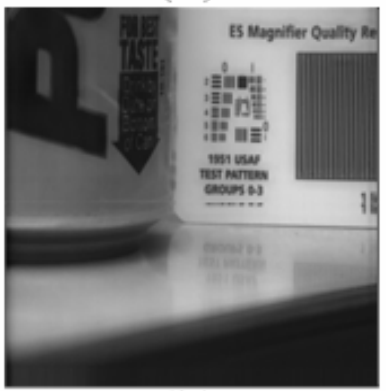

(h)

Figure 8: Results for pepsi image a) focus on pepsi container b) focus on barcode c) Result for PCA method d) Result for Contrast pyramid e) Result for Gradient Pyramid f) Result for Pu et al. [20] method $\mathrm{g}, \mathrm{h})$ Result for proposed method using first and second definition of directive contrast. 


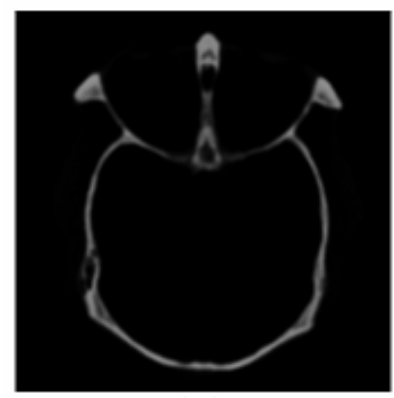

(a)

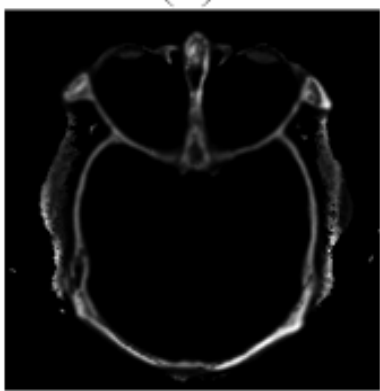

(e)

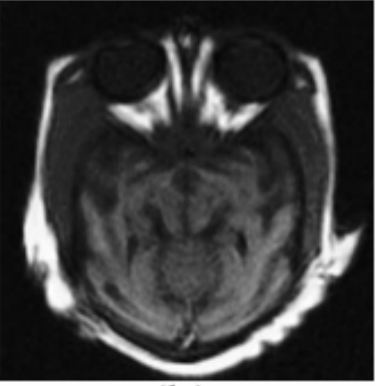

(b)

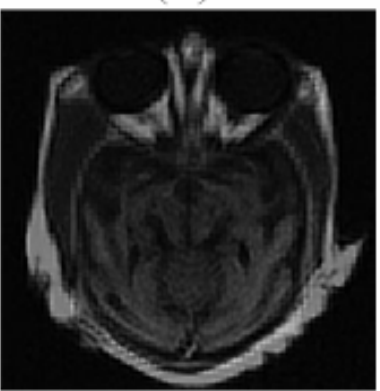

(f)

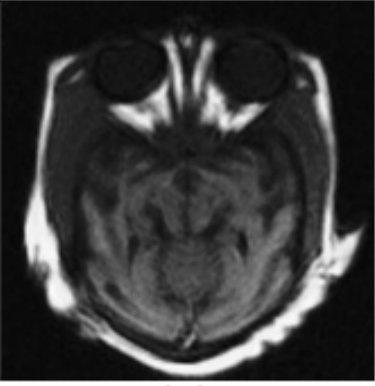

(c)

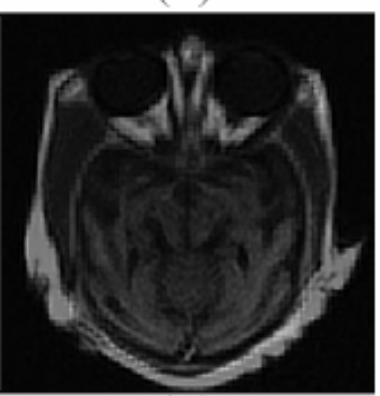

(g)

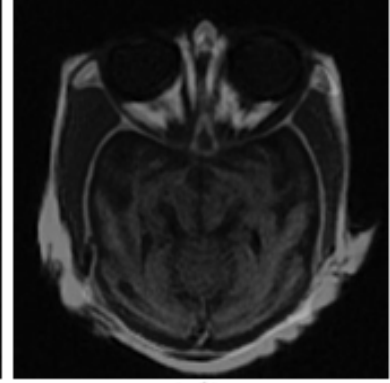

(d)

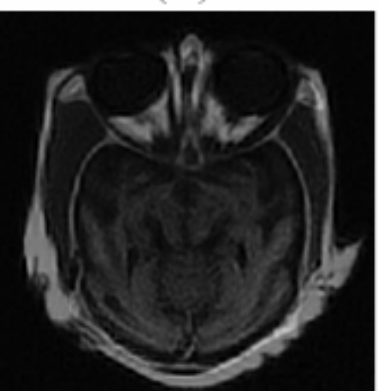

(h)

Figure 9: Results for Medical images a) CT image b) MRI image c) Result for PCA method d) Result for Contrast pyramid e) Result for Gradient Pyramid f) Result for Pu et al. [20] method g,h) Result for proposed method using first and second definition of directive contrast.

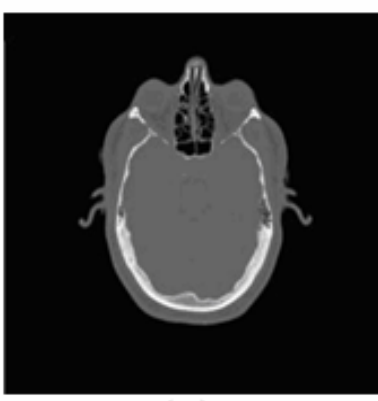

(a)

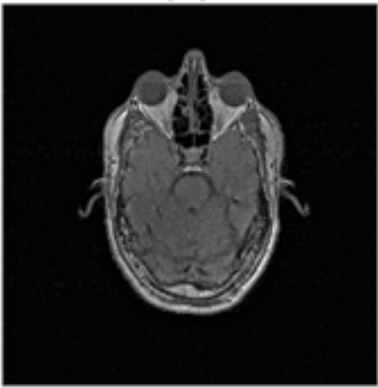

(e)

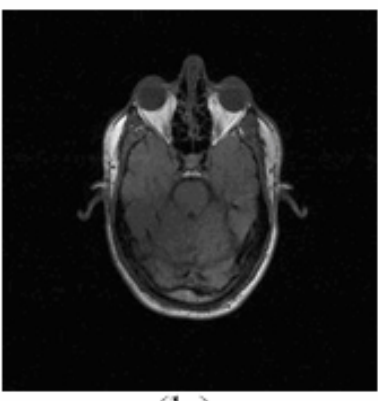

(b)

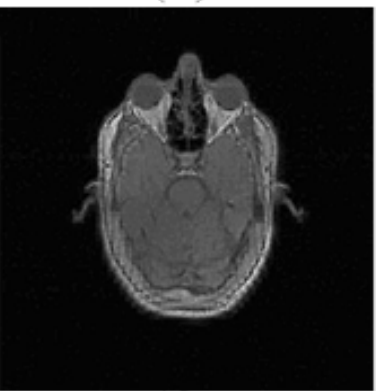

(f)

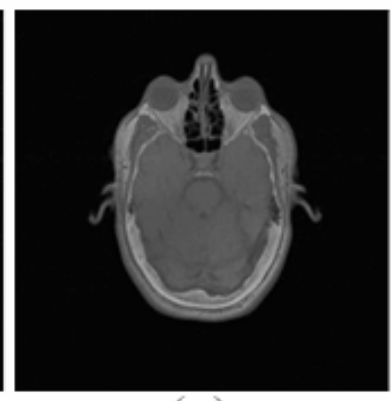

(c)

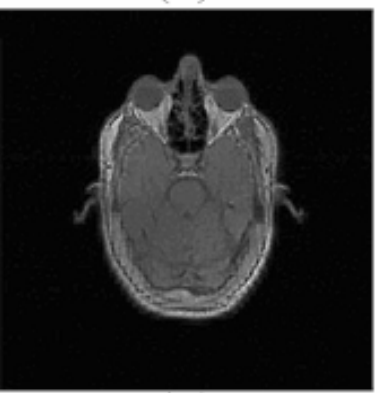

(

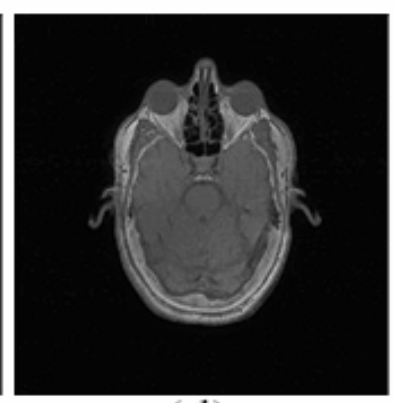

(d)

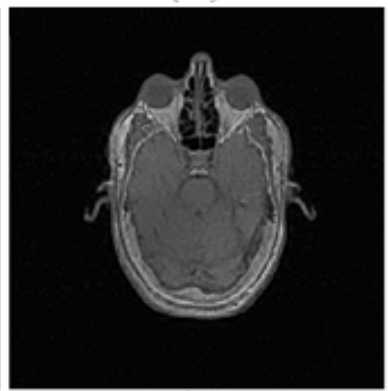

(h)

Figure 10: Results for Medical images a) CT image b) MRI image c) Result for PCA method d) Result for Contrast pyramid e) Result for Gradient Pyramid f) Result for Pu et al. [20] method g,h) Result for proposed method using first and second definition of directive contrast. 


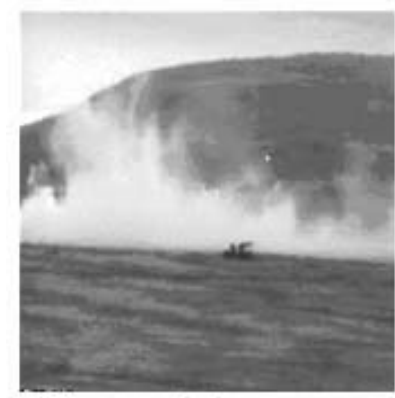

(a)

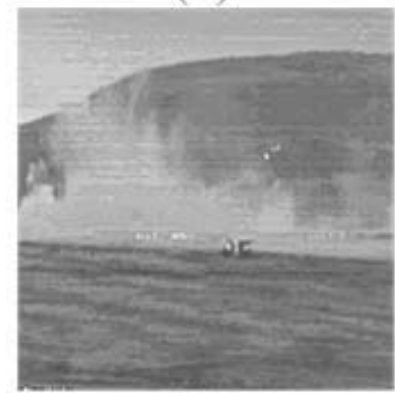

(e)

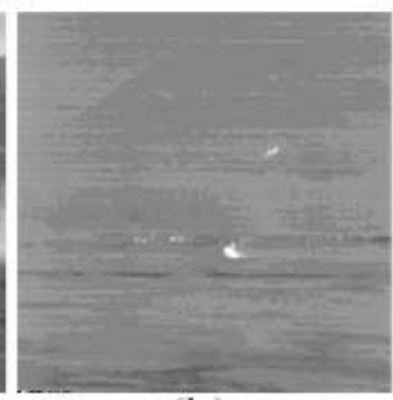

(b)

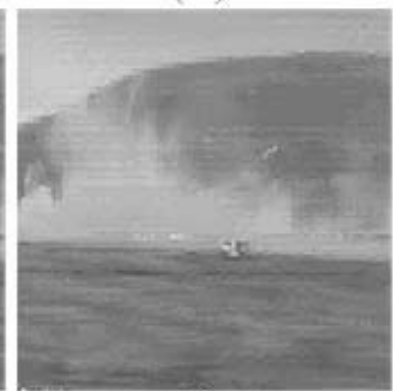

(f)

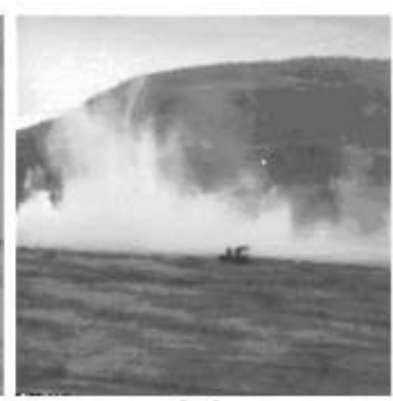

(c)

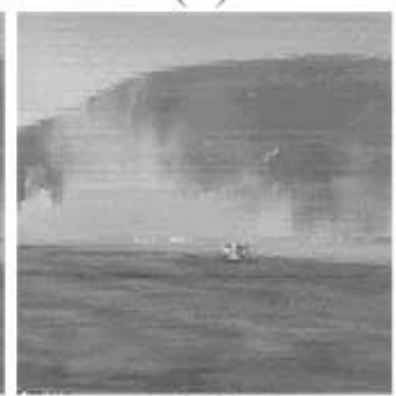

(g)

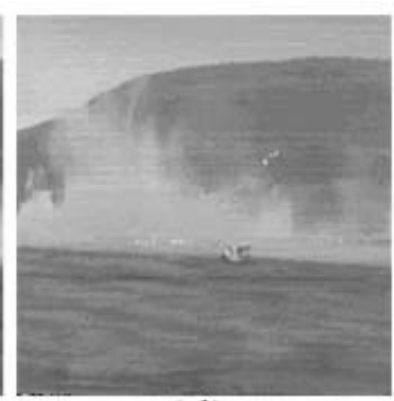

(d)

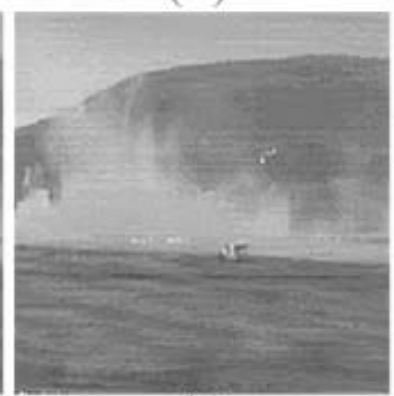

(h)

Figure 11: Results for Military surveillance a) visual image b) IR image c) Result for PCA method d) Result for Contrast pyramid e) Result for Gradient Pyramid f) Result for Pu et al. [20] method g,h) Result for proposed method using first and second definition of directive contrast.

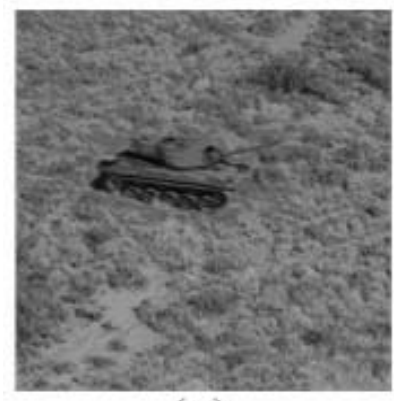

(a)

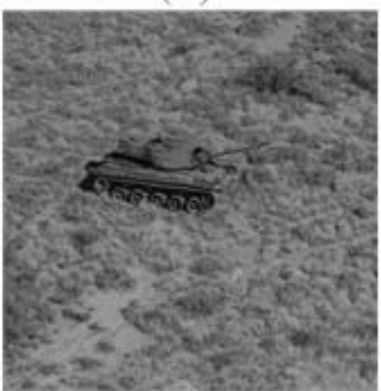

(e)

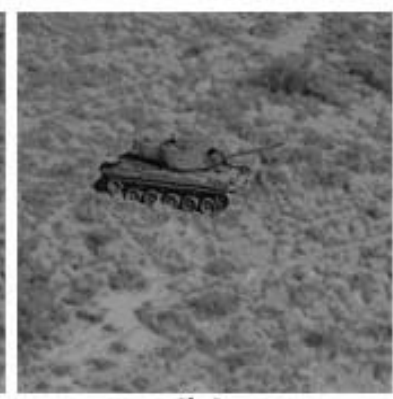

(b)

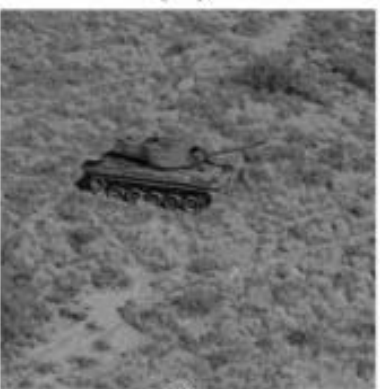

(f)

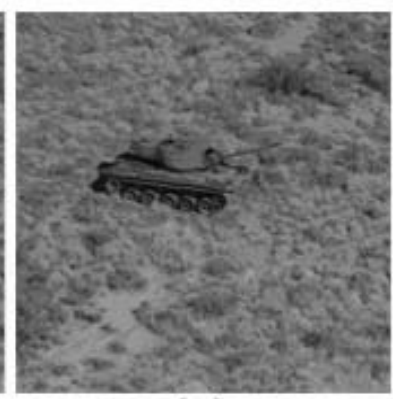

(c)

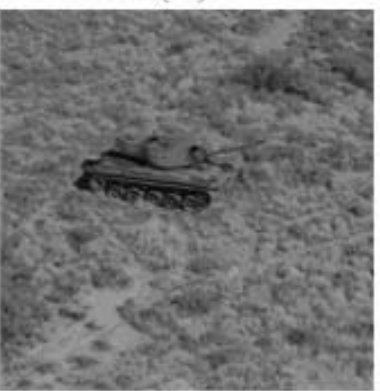

(

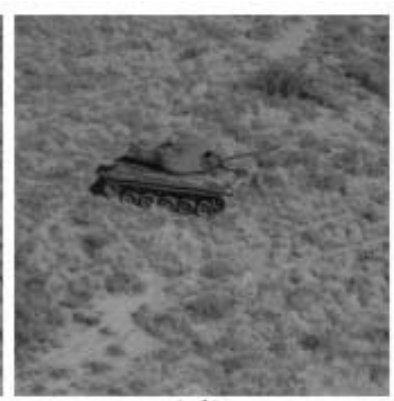

(d)

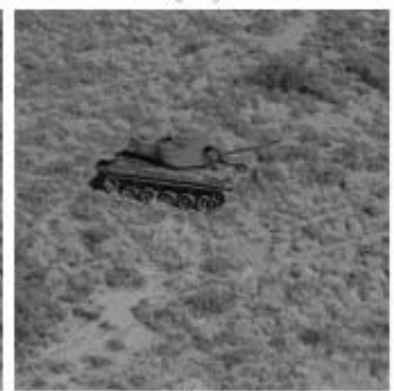

(h)

Figure 12: Results for Military surveillance identify the motion of a tank a) image in which Tank is motion blurred b) image in which background is clear c) Result for PCA method d) Result for Contrast pyramid e) Result for Gradient Pyramid f) Result for Pu et al. [20] method g,h) Result for proposed method using first and second definition of directive contrast. 


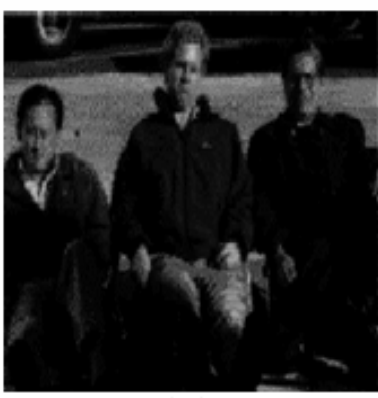

(a)

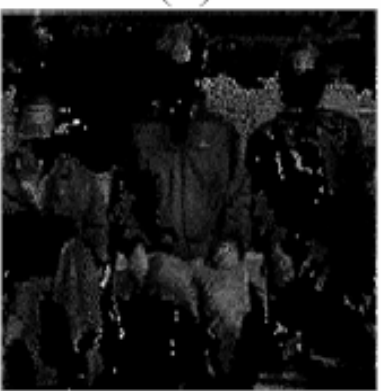

(e)

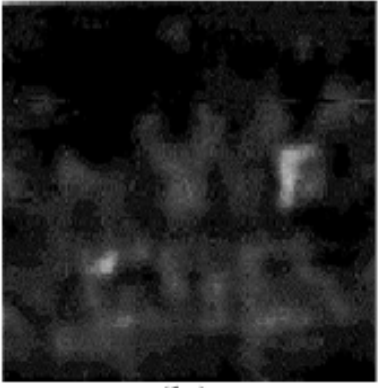

(b)

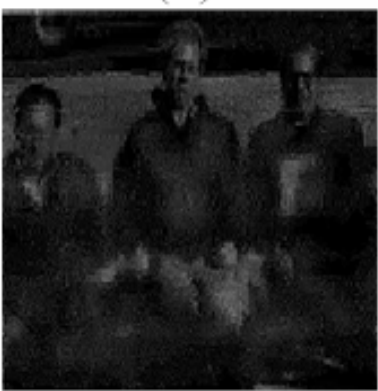

(f)

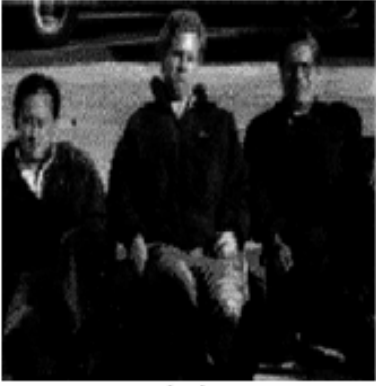

(c)

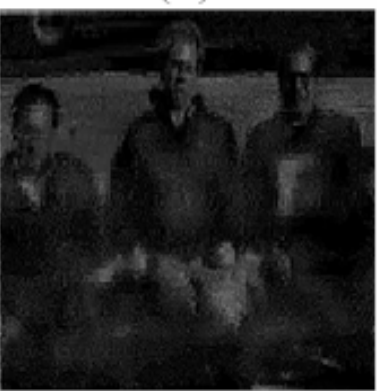

(g)

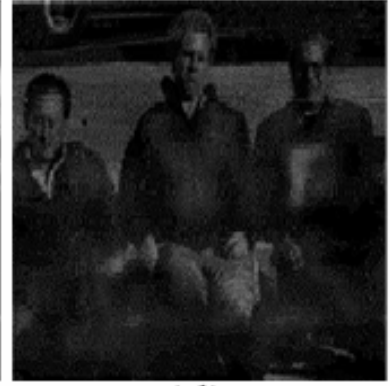

(d)

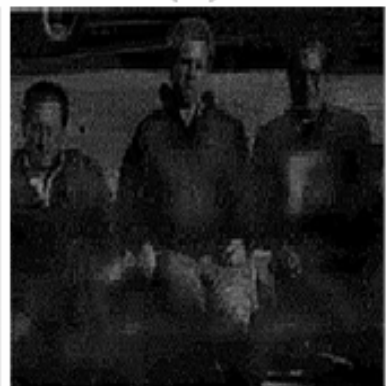

(h)

Figure 13: Results for Concealed weapon detection a) visual image b) MMW image c) Result for PCA method d) Result for Contrast pyramid e) Result for Gradient Pyramid f) Result for Pu et al. [20] method $\mathrm{g}, \mathrm{h})$ Result for proposed method using first and second definition of directive contrast.

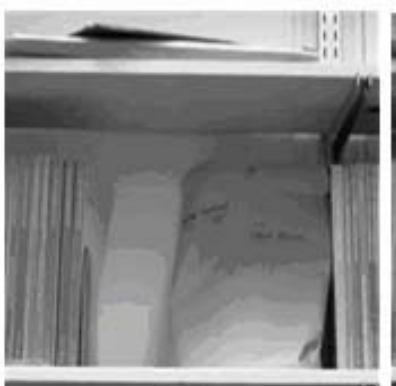

(a)

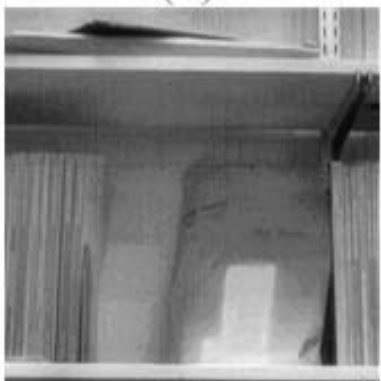

(e)

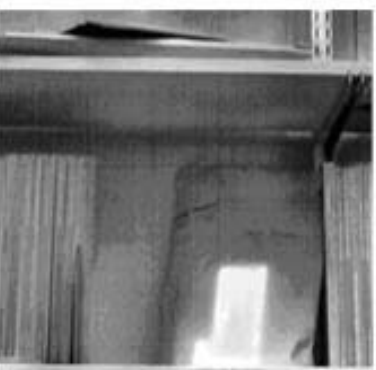

(b)

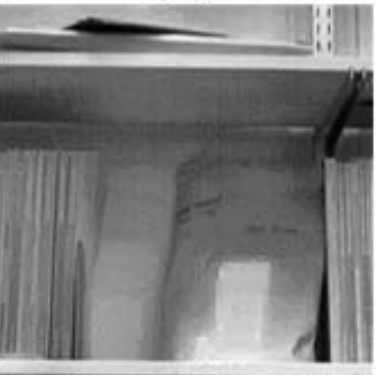

(f)

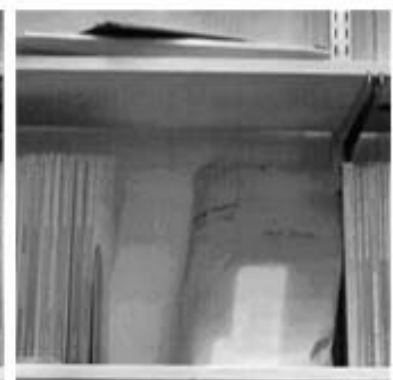

(c)

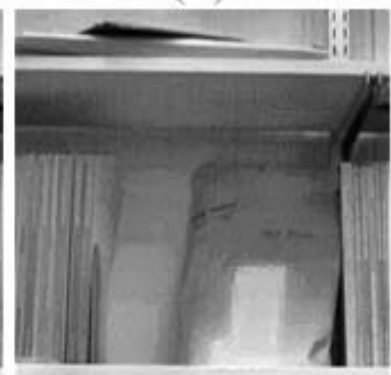

(g)

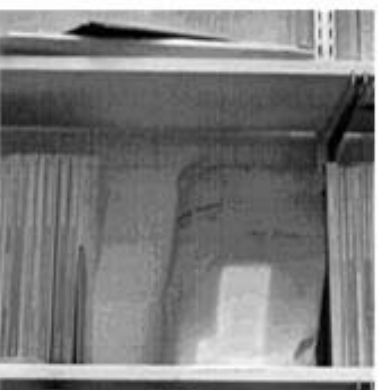

(d)

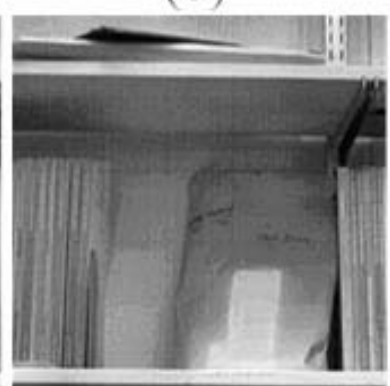

(h)

Figure 14: Results for Concealed weapon detection a) visual image b) IR image c) Result for PCA method d) Result for Contrast pyramid e) Result for Gradient Pyramid f) Result for Pu et al. [20] method g,h) Result for proposed method using first and second definition of directive contrast. 


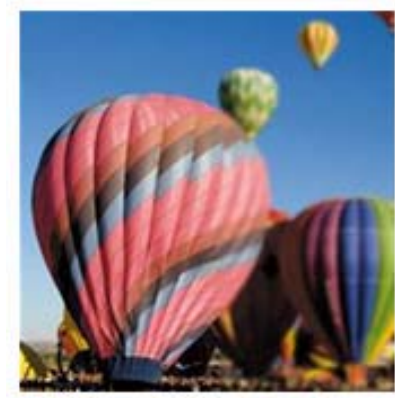

(a)

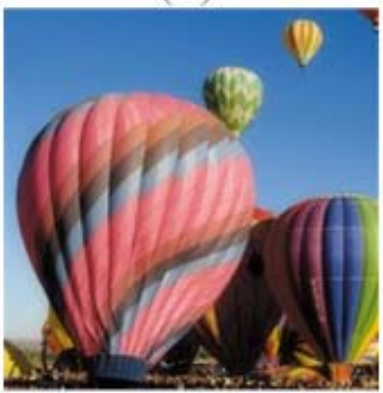

(e)

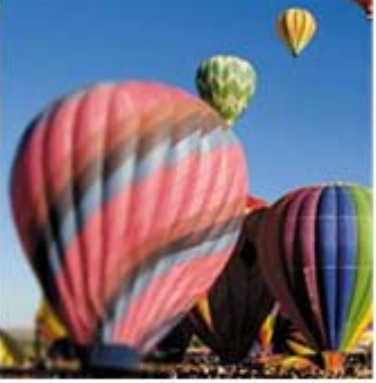

(b)

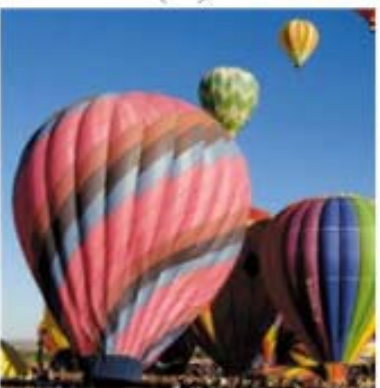

(f)

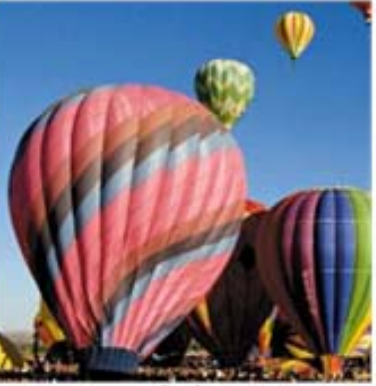

(c)

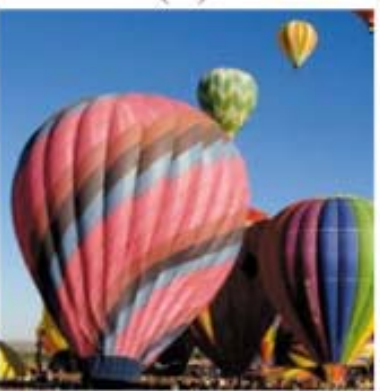

(g)

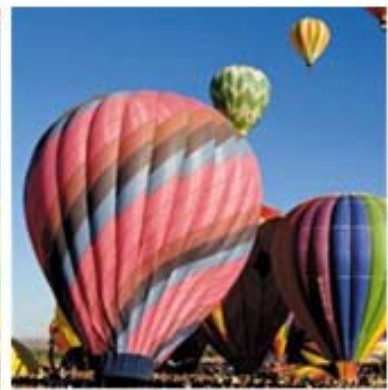

(d)

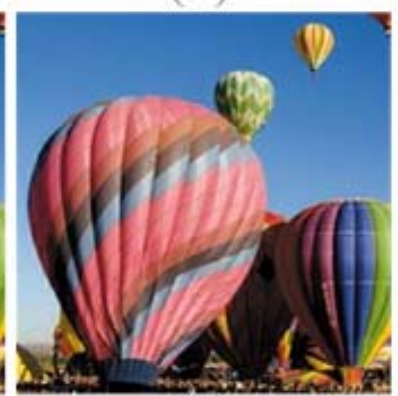

(h)

Figure 15: Results for balloon image a) Left side blurred image b) Right side blurred image c) Result for PCA method d) Result for Contrast pyramid e) Result for Gradient Pyramid f) Result for Pu et al. [20] method g,h) Result for proposed method using first and second definition of directive contrast.

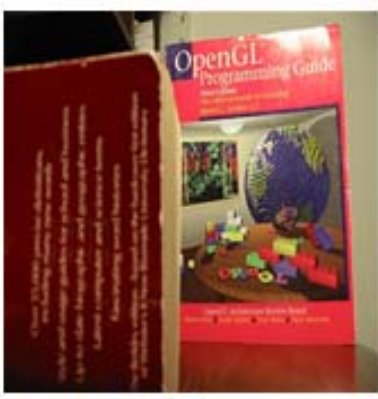

(a)

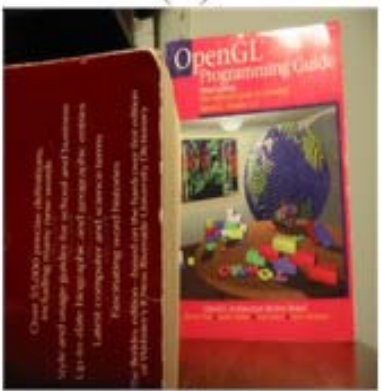

(e)

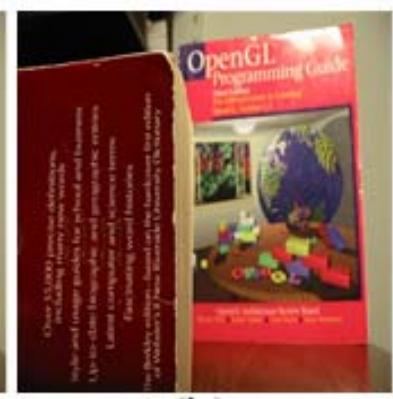

(b)

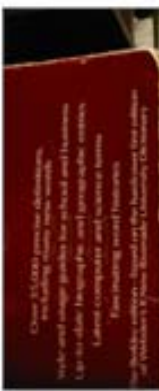

(f)

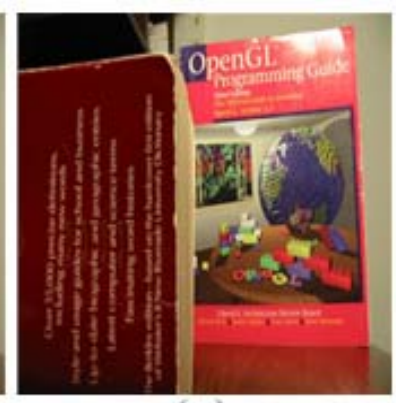

(c)

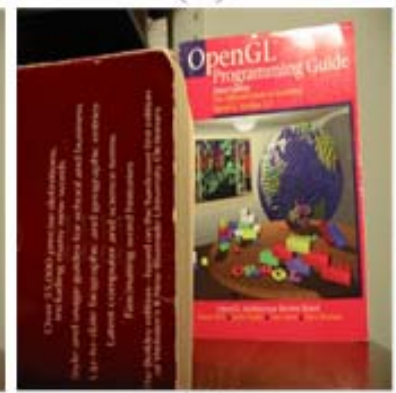

(g)

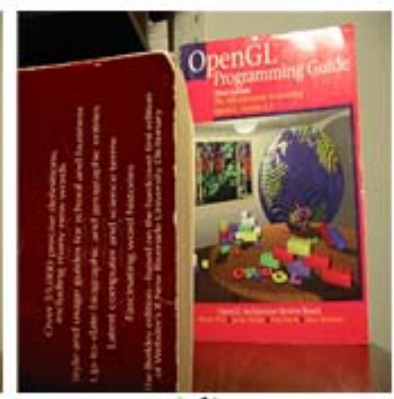

(d)

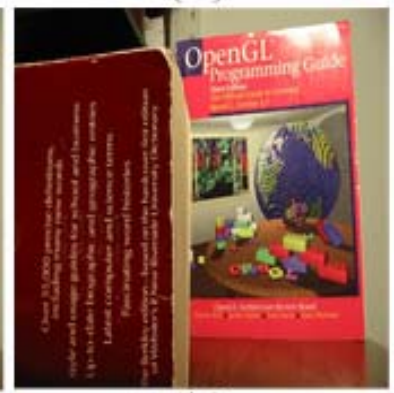

(h)

Figure 16: Results for Book image a) focus on OpenGL book b) focus on another book c) Result for PCA method d) Result for Contrast pyramid e) Result for Gradient Pyramid f) Result for Pu et al. [20] method $\mathrm{g}, \mathrm{h})$ Result for proposed method using first and second definition of directive contrast. 


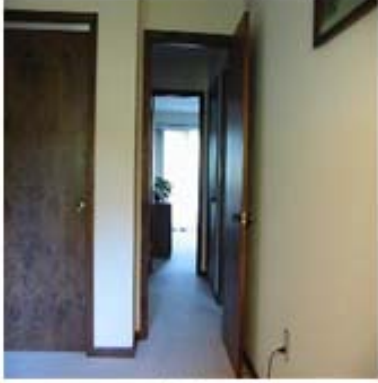

(a)

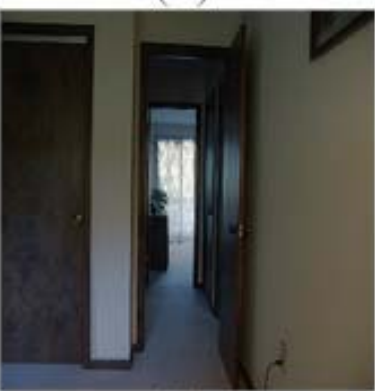

(e)

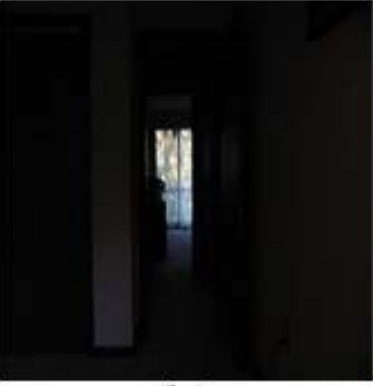

(b)

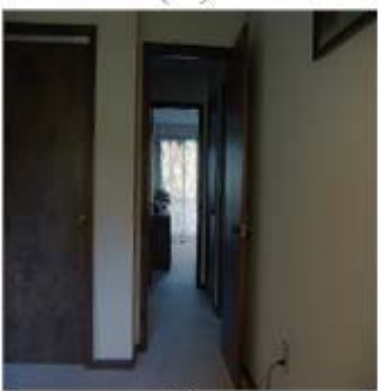

(f)

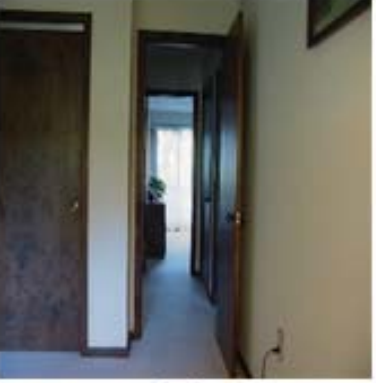

(c)

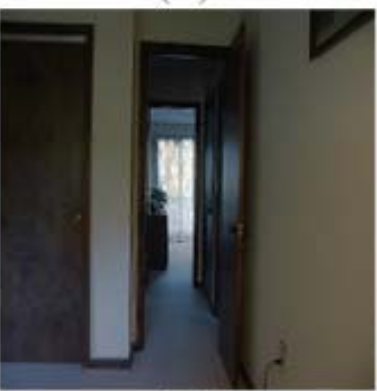

(g)

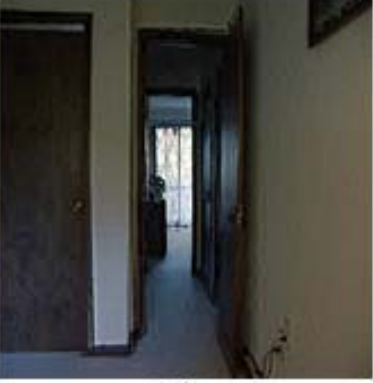

(d)

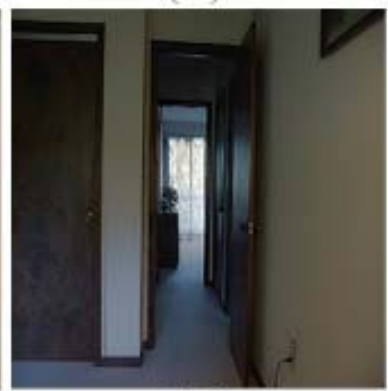

(h)

Figure 17: Results for House images a) focus on Inside the house b) focus on Onside the house c) Result for PCA method d) Result for Contrast pyramid e) Result for Gradient Pyramid f) Result for Pu et al. [20] method g,h) Result for proposed method using first and second definition of directive contrast.

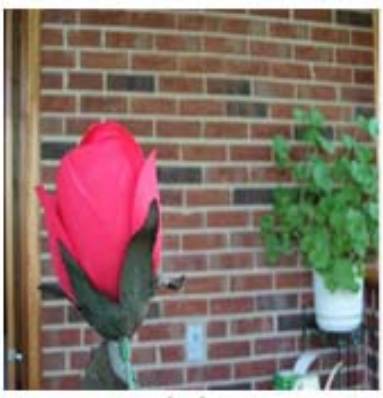

(a)

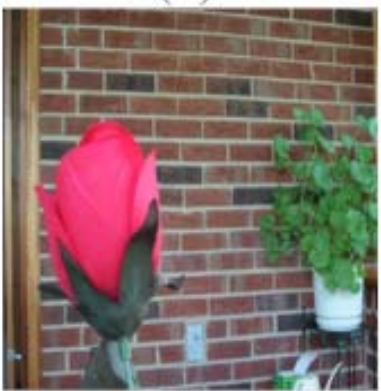

(e)

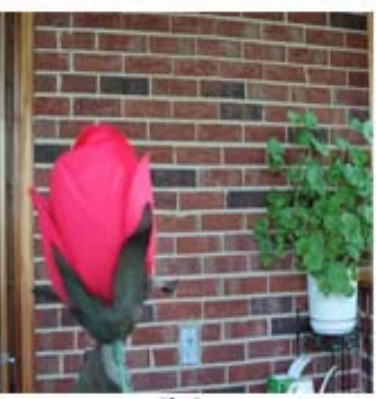

(b)

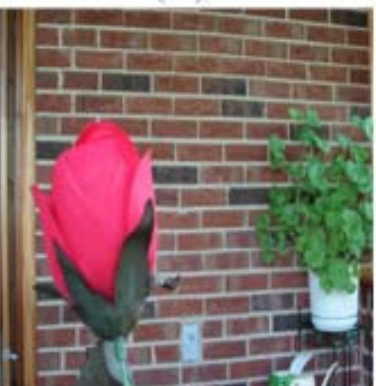

(f)

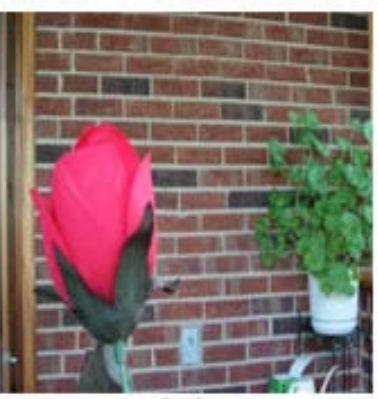

(c)

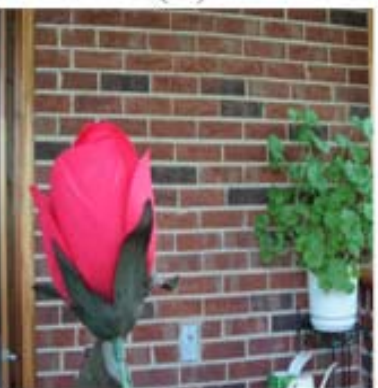

(g)

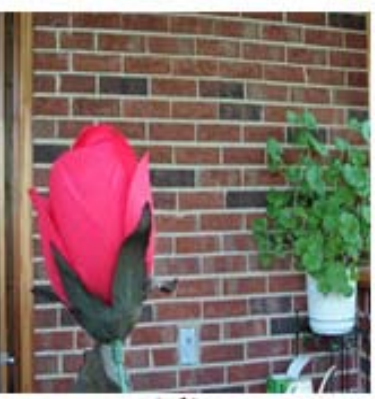

(d)

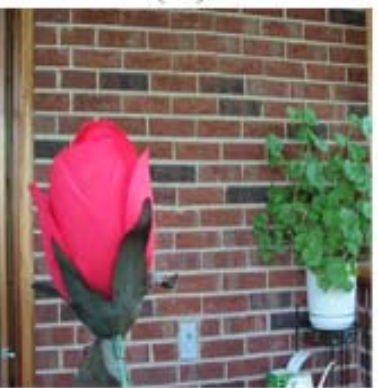

(h)

Figure 18: Results for Rose image a) focus on Rose b) focus on pot c) Result for PCA method d) Result for Contrast pyramid e) Result for Gradient Pyramid f) Result for Pu et al. [20] method g,h) Result for proposed method using first and second definition of directive contrast 


\begin{tabular}{|c|c|c|c|c|c|c|c|}
\hline \multirow[b]{2}{*}{ Images } & \multirow{2}{*}{$\begin{array}{l}\text { Evaluation } \\
\text { Indices }\end{array}$} & \multirow{2}{*}{$\begin{array}{c}\text { PCA } \\
\text { (MS Rule) }\end{array}$} & \multirow{2}{*}{$\begin{array}{c}\text { Gradient } \\
\text { pyramid } \\
\text { Burt et al. } \\
{[11]}\end{array}$} & \multirow{2}{*}{$\begin{array}{c}\text { Contrast } \\
\text { pyramid } \\
\text { Toet et al. } \\
\text { [13] }\end{array}$} & \multirow{2}{*}{$\begin{array}{l}\text { Pu method } \\
\text { Pu et al. } \\
\text { [20] }\end{array}$} & \multicolumn{2}{|c|}{ Proposed method } \\
\hline & & & & & & $\begin{array}{l}\text { Using D.C. } \\
\mathrm{I}^{\text {st }} \text { definition }\end{array}$ & $\begin{array}{l}\text { Using D.C. } \\
\text { II }^{\text {nd }} \text { definition }\end{array}$ \\
\hline \multirow{7}{*}{$\begin{array}{c}\text { Mandrill } \\
\text { (Figure 5) }\end{array}$} & Mean & 129.3061 & 129.3052 & 129.0349 & 129.3461 & 129.3772 & 129.2966 \\
\hline & S.D. & 5.6798 & 5.2925 & 5.5893 & 5.4142 & 5.3484 & 5.3763 \\
\hline & Entropy & 4.8986 & 4.9785 & 5.0607 & 5.0157 & 4.9869 & 5.0217 \\
\hline & D.E. & 0.2018 & 0.1219 & 0.0397 & 0.0847 & 0.1135 & 0.0787 \\
\hline & A.G & 20.4265 & 32.6696 & 39.1845 & 35.6255 & 32.1015 & 37.2597 \\
\hline & PSNR & 24.2976 & 28.1692 & 34.1770 & 26.1722 & 24.2981 & 28.6002 \\
\hline & CC. & 0.9948 & 0.9979 & 0.9994 & 0.9965 & 0.9947 & 0.9979 \\
\hline \multirow{7}{*}{$\begin{array}{c}\text { Pepper } \\
\text { (Figure 6) }\end{array}$} & Mean & 119.7841 & 119.7475 & 119.1812 & 119.8029 & 119.8227 & 119.7058 \\
\hline & S.D. & 9.8550 & 9.6775 & 10.0674 & 9.7441 & 9.7856 & 9.6977 \\
\hline & Entropy & 5.1851 & 5.1920 & 5.2221 & 5.1952 & 5.1941 & 5.2033 \\
\hline & D.E. & 0.0785 & 0.0715 & 0.0415 & 0.0683 & 0.0694 & 0.0603 \\
\hline & A.G & 12.9844 & 15.0344 & 18.6062 & 15.2334 & 15.4016 & 16.3751 \\
\hline & PSNR & 26.0852 & 27.0795 & 31.1527 & 25.5584 & 25.4823 & 27.0574 \\
\hline & CC. & 0.9964 & 0.9972 & 0.9990 & 0.9954 & 0.9957 & 0.9972 \\
\hline \multirow{4}{*}{$\begin{array}{c}\text { Hoed } \\
\text { (Figure 7) }\end{array}$} & Mean & 95.9700 & 95.9091 & 95.3119 & 95.9688 & 96.0067 & 95.9656 \\
\hline & S.D. & 19.1303 & 18.3773 & 19.0860 & 19.7839 & 19.5942 & 18.4173 \\
\hline & Entropy & 5.2883 & 5.3394 & 5.3557 & 5.3226 & 5.3100 & 5.3516 \\
\hline & A.G & 15.2689 & 24.2124 & 28.2695 & 20.8926 & 17.4989 & 26.7934 \\
\hline \multirow{4}{*}{$\begin{array}{c}\text { Pepsi } \\
\text { (Figure 8) }\end{array}$} & Mean & 101.4676 & 102.2890 & 97.5135 & 102.2377 & 102.2680 & 102.2214 \\
\hline & S.D. & 11.3812 & 10.0691 & 11.2571 & 10.4515 & 10.5085 & 10.5683 \\
\hline & Entropy & 5.1267 & 5.1436 & 4.7704 & 5.1276 & 5.1091 & 5.1570 \\
\hline & A.G & 12.9011 & 11.6214 & 16.5407 & 12.6104 & 12.5940 & 13.1155 \\
\hline
\end{tabular}

Table 1 Evaluation Indices for Defocused/Multi-focus images

\begin{tabular}{|c|c|c|c|c|c|c|c|}
\hline \multirow[b]{2}{*}{ Images } & \multirow{2}{*}{$\begin{array}{l}\text { Evaluation } \\
\text { Indices }\end{array}$} & \multirow{2}{*}{$\begin{array}{c}\text { PCA (MS } \\
\text { Rule) }\end{array}$} & \multirow{2}{*}{$\begin{array}{c}\text { Gradient } \\
\text { pyramid } \\
\text { Burt et al. } \\
\text { [11] }\end{array}$} & \multirow{2}{*}{$\begin{array}{c}\text { Contrast } \\
\text { pyramid } \\
\text { Toet et al. } \\
{[13]}\end{array}$} & \multirow{2}{*}{$\begin{array}{l}\text { Pu method } \\
\text { Pu } \text { et al. } \\
\text { [20] }\end{array}$} & \multicolumn{2}{|c|}{ Proposed method } \\
\hline & & & & & & $\begin{array}{l}\text { Using D.C. } \\
\mathrm{I}^{\text {st }} \text { definition }\end{array}$ & $\begin{array}{l}\text { Using D.C. } \\
\text { II }^{\text {nd }} \text { definition }\end{array}$ \\
\hline \multirow{4}{*}{$\begin{array}{l}\text { Medical } \\
\text { Image I } \\
\text { (Figure 9) }\end{array}$} & Mean & 53.3208 & 30.2787 & 8.5074 & 29.9726 & 30.0760 & 30.0860 \\
\hline & S.D. & 20.8549 & 11.0581 & 13.1892 & 11.2025 & 11.7242 & 11.6084 \\
\hline & Entropy & 4.5762 & 4.1203 & 1.3719 & 4.1550 & 4.1643 & 4.1724 \\
\hline & A.G & 20.0904 & 12.8612 & 10.2841 & 13.7915 & 14.0389 & 14.3634 \\
\hline \multirow{4}{*}{$\begin{array}{c}\text { Medical } \\
\text { Image II } \\
\text { (Figure 10) }\end{array}$} & Mean & 28.1003 & 27.4298 & 26.5784 & 26.9725 & 26.9882 & 27.1354 \\
\hline & S.D. & 21.5604 & 21.1908 & 22.2698 & 21.0522 & 21.1365 & 21.1827 \\
\hline & Entropy & 2.3404 & 2.8217 & 2.8220 & 2.9210 & 2.9321 & 2.9417 \\
\hline & A.G & 8.4774 & 11.5131 & 11.7219 & 11.8768 & 13.2678 & 14.7351 \\
\hline
\end{tabular}




\begin{tabular}{|c|c|c|c|c|c|c|c|}
\hline \multirow[b]{2}{*}{ Images } & \multirow{2}{*}{$\begin{array}{l}\text { Evaluation } \\
\text { Indices }\end{array}$} & \multirow{2}{*}{$\begin{array}{c}\text { PCA (MS } \\
\text { Rule) }\end{array}$} & \multirow{2}{*}{$\begin{array}{c}\text { Gradient } \\
\text { pyramid } \\
\text { Burt et al. } \\
\text { [11] }\end{array}$} & \multirow{2}{*}{$\begin{array}{c}\text { Contrast } \\
\text { pyramid } \\
\text { Toet et al. } \\
{[13]}\end{array}$} & \multirow{2}{*}{$\begin{array}{l}\text { Pu method } \\
\text { Pu et al. } \\
\text { [20] }\end{array}$} & \multicolumn{2}{|c|}{ Proposed method } \\
\hline & & & & & & $\begin{array}{l}\text { Using D.C. } \\
\mathrm{I}^{\text {st }} \text { definition }\end{array}$ & $\begin{array}{l}\text { Using D.C. } \\
\text { II }^{\text {nd }} \text { definition }\end{array}$ \\
\hline \multirow{4}{*}{$\begin{array}{c}\text { Sea } \\
\text { (Figure 11) }\end{array}$} & Mean & 144.8179 & 144.9044 & 144.5866 & 144.9410 & 144.9639 & 144.9087 \\
\hline & S.D. & 4.3992 & 4.3882 & 4.4801 & 4.3894 & 4.4103 & 4.4173 \\
\hline & Entropy & 4.5424 & 4.5088 & 4.6195 & 4.5340 & 4.5290 & 4.5625 \\
\hline & A.G & 10.1847 & 9.0253 & 11.3477 & 9.1645 & 10.9108 & 11.3887 \\
\hline \multirow{4}{*}{$\begin{array}{c}\text { Tank } \\
\text { (Figure 12) }\end{array}$} & Mean & 109.1835 & 109.1276 & 109.1688 & 109.2095 & 109.2261 & 109.2894 \\
\hline & S.D. & 4.5694 & 4.5932 & 4.4960 & 4.5268 & 4.4891 & 4.4886 \\
\hline & Entropy & 3.0995 & 4.2327 & 3.7350 & 4.3382 & 4.3685 & 4.3357 \\
\hline & A.G & 15.6896 & 16.1044 & 19.2107 & 17.4370 & 17.3148 & 19.9442 \\
\hline
\end{tabular}

Table 3 Evaluation Indices for Military Surveillance

\begin{tabular}{|c|c|c|c|c|c|c|c|}
\hline \multirow[b]{2}{*}{ Images } & \multirow{2}{*}{$\begin{array}{l}\text { Evaluation } \\
\text { Indices }\end{array}$} & \multirow{2}{*}{$\begin{array}{c}\text { PCA (MS } \\
\text { Rule) }\end{array}$} & \multirow{2}{*}{$\begin{array}{c}\text { Gradient } \\
\text { pyramid } \\
\text { Burt et al. } \\
{[11]}\end{array}$} & \multirow{2}{*}{$\begin{array}{c}\text { Contrast } \\
\text { pyramid } \\
\text { Toet et al. } \\
\text { [13] }\end{array}$} & \multirow{2}{*}{$\begin{array}{l}\text { Pu method } \\
\text { Pu et al. } \\
\text { [20] }\end{array}$} & \multicolumn{2}{|c|}{ Proposed method } \\
\hline & & & & & & $\begin{array}{l}\text { Using D.C. } \\
\mathrm{I}^{\text {st }} \text { definition }\end{array}$ & $\begin{array}{l}\text { Using D.C. } \\
\text { II }^{\text {nd }} \text { definition }\end{array}$ \\
\hline \multirow{4}{*}{$\begin{array}{c}\text { Gun } \\
\text { (Figure 13) }\end{array}$} & Mean & 26.0617 & 26.4263 & 15.6564 & 26.0583 & 26.1908 & 26.3896 \\
\hline & S.D. & 3.3351 & 3.3993 & 3.6343 & 3.3262 & 3.4156 & 3.6044 \\
\hline & Entropy & 2.7951 & 4.1115 & 2.3052 & 4.1391 & 4.1251 & 4.1593 \\
\hline & A.G & 17.7208 & 18.2588 & 16.4370 & 19.7084 & 20.0201 & 26.8247 \\
\hline \multirow{4}{*}{$\begin{array}{c}\text { Shelf } \\
\text { (Figure 14) }\end{array}$} & Mean & 121.3187 & 121.4539 & 121.1608 & 121.4811 & 121.4534 & 121.5156 \\
\hline & S.D. & 7.4451 & 7.3002 & 7.3867 & 7.3905 & 7.4535 & 7.5594 \\
\hline & Entropy & 4.5605 & 5.1462 & 5.2169 & 5.1988 & 5.1947 & 5.2051 \\
\hline & A.G & 14.3625 & 13.7997 & 15.4880 & 15.6119 & 16.6643 & 17.3825 \\
\hline
\end{tabular}

Table 4 Evaluation Indices for Concealed Weapon detection 


\begin{tabular}{|c|c|c|c|c|c|c|c|}
\hline \multirow[b]{2}{*}{ Images } & \multirow{2}{*}{$\begin{array}{l}\text { Evaluation } \\
\text { Indices }\end{array}$} & \multirow{2}{*}{$\begin{array}{c}\text { PCA (MS } \\
\text { Rule) }\end{array}$} & \multirow{2}{*}{$\begin{array}{c}\text { Gradient } \\
\text { pyramid } \\
\text { Burt et al. } \\
\text { [11] }\end{array}$} & \multirow{2}{*}{$\begin{array}{c}\text { Contrast } \\
\text { pyramid } \\
\text { Toet et al. } \\
{[13]}\end{array}$} & \multirow{2}{*}{$\begin{array}{l}\text { Pu method } \\
\text { Pu et al. } \\
\text { [20] }\end{array}$} & \multicolumn{2}{|c|}{ Proposed method } \\
\hline & & & & & & $\begin{array}{l}\text { Using D.C. } \\
I^{\text {st }} \text { definition }\end{array}$ & $\begin{array}{l}\text { Using D.C. } \\
\text { I }^{\text {nd }} \text { definition }\end{array}$ \\
\hline \multirow{4}{*}{$\begin{array}{l}\text { Balloon } \\
\text { (Figure 15) }\end{array}$} & Mean & 112.4463 & 113.3382 & 113.3182 & 113.3575 & 113.3903 & 113.3960 \\
\hline & S.D. & 12.7144 & 12.7523 & 12.6914 & 12.6992 & 12.7121 & 12.7246 \\
\hline & Entropy & 5.2290 & 5.2792 & 5.3032 & 5.3017 & 5.3017 & 5.3052 \\
\hline & A.G & 19.8124 & 20.5473 & 25.0207 & 21.9500 & 21.7100 & 24.8516 \\
\hline \multirow{4}{*}{$\begin{array}{c}\text { Book } \\
\text { (Figure 16) }\end{array}$} & Mean & 83.9942 & 83.7962 & 83.8656 & 84.0912 & 84.0964 & 84.1263 \\
\hline & S.D. & 17.8841 & 17.2696 & 17.4464 & 17.5524 & 17.8190 & 18.0247 \\
\hline & Entropy & 4.9668 & 4.8912 & 4.9471 & 4.9649 & 4.9698 & 4.9832 \\
\hline & A.G & 20.8744 & 23.7363 & 24.3569 & 27.9483 & 28.6338 & 29.8165 \\
\hline \multirow{4}{*}{$\begin{array}{c}\text { House } \\
\text { (Figure 17) }\end{array}$} & Mean & 63.3324 & 63.5633 & 62.4907 & 63.5826 & 63.6090 & 63.6306 \\
\hline & S.D. & 15.3203 & 15.6794 & 16.4323 & 15.7182 & 15.7667 & 16.0093 \\
\hline & Entropy & 4.0969 & 4.7763 & 4.7818 & 4.7749 & 4.7633 & 4.7847 \\
\hline & A.G & 9.1806 & 9.1470 & 10.5182 & 8.4650 & 10.2285 & 11.0841 \\
\hline \multirow{4}{*}{$\begin{array}{c}\text { Rose } \\
\text { (Figure 18) }\end{array}$} & Mean & 106.9310 & 106.6975 & 106.5763 & 107.0156 & 107.0482 & 107.0803 \\
\hline & S.D. & 11.6534 & 11.6517 & 11.5850 & 12.5212 & 12.5266 & 12.5291 \\
\hline & Entropy & 5.0688 & 5.0380 & 5.1236 & 5.0905 & 5.0964 & 5.1061 \\
\hline & A.G & 19.1056 & 19.3669 & 21.5067 & 23.2199 & 23.9831 & 24.6456 \\
\hline
\end{tabular}

Table 5 Evaluation Indices for Colour images 